\title{
Aportes al conocimiento del Magmatismo de la Cordillera Central de Colombia en su Flanco Oriental: Área geotérmica de San Diego, Samaná, Caldas
}

\author{
Jesús Bernardo Rueda-Gutiérrez ${ }^{1^{*}}$
}

DOI: http://dx.doi.org/10.18273/revbol.v41n2-2019003 @ (1)

Forma de citar: Rueda-Gutiérrez, J.B. (2019). Aportes al conocimiento del Magmatismo de la Cordillera Central de Colombia en su Flanco Oriental: Área geotérmica de San Diego, Samaná, Caldas. Boletín de Geología, 41(2), 45-70. DOI: 10.18273/ revbol.v41n2-2019003

\section{RESUMEN}

Fueron caracterizados en el área geotérmica de San Diego, cinco cuerpos plutónicos, cuyas características químicas posicionan a cuatro unidades (Stock de Florencia, Batolito de Sonsón, Complejo de Samaná y Alaskita de Samaná) en el campo de los granitos tipo I, y a la unidad Intrusivo Gnéisico como granito tipo S. Todos presentan firmas químicas de Rb, Y y Nb típicas de granitoides de subducción, de serie calcoalcalina y tipo magnésicos. Dataciones U-Pb mediante LA-ICP-MS en circones

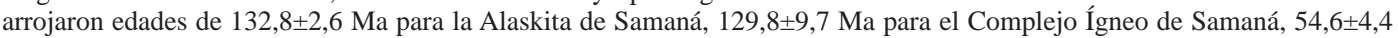
Ma para el Stock de Florencia y 47£11 Ma para el Batolito de Sonsón.

Nueve cuerpos porfiríticos andesiticos (P1+Anf) de los cuales cinco fueron reconocidos en las labores de campo de este trabajo, se expresan algunos de ellos con evidentes formas dómicas y matrices vítreas. Estos cuerpos porfiríticos presentan mayor grado de alteración hidrotermal (fílica y argílica) en especial en el sector de Puente Linda, controlados estructuralmente, con presencia de brechas orientadas este-oeste a lo largo del rio Samaná. Todos estos cuerpos con firmas adakiticas ( $\mathrm{Sr}$ entre 335,31 y 1160,25 ppm) presentan anomalía positiva de $\mathrm{Eu}_{\mathrm{N}} / \sqrt{ }\left(\mathrm{Sm}_{\mathrm{N}}{ }^{*} \mathrm{Gd}_{\mathrm{N}}\right)$ desde 1,34 a 2,07. El pórfido de Puente Linda $(\mathrm{Pl}+$ $\mathrm{Qz}+\mathrm{Anf} \pm \mathrm{Cb} \pm \mathrm{K} \pm \mathrm{Dck}$ ) tiene sobreimpuesta la mayor alteración en extensión y grado; datación U-Pb arrojó una edad de

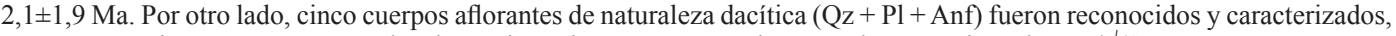
cuya geoquímica contrastante con las demás intrusiones, presentando anomalías negativas de $\mathrm{Eu}_{\mathrm{N}} / \sqrt{ }\left(\mathrm{Sm}_{\mathrm{N}}{ }^{*} \mathrm{Gd}_{\mathrm{N}}\right)$ desde 0,18 a 0,64. Finalmente, dos estructuras volcánicas, domo de San Diego $(\mathrm{Qz}+\mathrm{Pl}+\mathrm{Bt})$ y Domos del volcán El Escondido $(\mathrm{Pl}+\mathrm{Anf})$ se reconocen como evidencias de actividad volcánicas reciente; dataciones Ar-Ar registraron una edad Plateau de $89 \pm 4,4 \mathrm{Ka}$

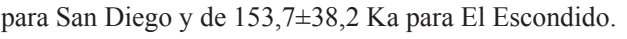

Palabras clave: San Diego; geotermia; dataciones U-Pb; dataciones Ar-Ar; geoquímica.

\section{Contributions to the Magmatism knowledge of the Central Cordillera of Colombia in its Eastern Flank: Geothermal Area of San Diego, Samaná, Caldas}

\begin{abstract}
Five plutonic bodies were characterized in the San Diego geothermal area, whose chemical characteristics position four units (Florencia Stock, Sonsón Batholith, Samaná Complex and Samaná Alaskite) in the field of granites type I, and the Gneissic Intrusive as granite type $\mathrm{S}$. All have chemical signatures of $\mathrm{Rb}, \mathrm{Y}$ and $\mathrm{Nb}$ typical of subduction environment granitoids, calcoalcaline series and magnesium type. The U-Pb data by LA-ICP-MS in zircons showed ages of $132.8 \pm 2.6$ my for the Samaná Alaskite, 129.8 \pm 9.7 my for the Samaná Igneous Complex, 54.6 \pm 4.4 my for the Florencia Stock and $47 \pm 11$ my for the Sonsón Batholith.

Nine andesitic porphyritic bodies ( $\mathrm{Pl}+\mathrm{Anf})$ of which five were recognized in this work, are expressed some of them with evident domic forms and vitreous matrices. These porphyritic bodies present a greater degree of hydrothermal alteration (phyllic and argillic), especially in the Puente Linda sector, structurally controlled, with the presence of oriented breccias (EW) along the Samaná River. All of these bodies with adakitic signatures (Sr between 335.31 and 1160.25 ppm) have positive anomaly $\mathrm{Eu}_{\mathrm{N}} / \sqrt{ }\left(\mathrm{Sm}_{\mathrm{N}} * \mathrm{Gd}_{\mathrm{N}}\right)$ from 1.34 to 2.07 . The Puente Linda porphyry $(\mathrm{Pl}+\mathrm{Qz}+\mathrm{Anf} \pm \mathrm{Cb} \pm \mathrm{K} \pm \mathrm{Dck})$ has superimposed the greater alteration in extension and degree; $\mathrm{U}-\mathrm{Pb}$ dating in zircons, showed an age of $2.1 \pm 1.9 \mathrm{Ma}$. On the other hand, five dacite bodies $(\mathrm{Qz}+\mathrm{Pl}+\mathrm{Anf})$ were equally recognized and characterized, whose geochemistry contrasted with that of other intrusions, with negative anomalies $\mathrm{Eu}_{\mathrm{N}} / \sqrt{ }\left(\mathrm{Sm}_{\mathrm{N}}{ }^{*} \mathrm{Gd}_{\mathrm{N}}\right)$ from 0.18 to 0.64. Finally, two volcanic structures, San Diego dome (Qz $+\mathrm{Pl}+\mathrm{Bt})$ and El Escondido volcano domes (Pl + Anf) are recognized as evidence of recent volcanic activity; Ar-Ar dating recorded a Plateau age of $89 \pm 4.4 \mathrm{Ka}$ for San Diego and 153.7 $\pm 38.2 \mathrm{Ka}$ for El Escondido.
\end{abstract}

Keywords: San Diego; geothermal; U-Pb dating; Ar-Ar dating; geochemistry.

${ }^{1}$ Grupo de Exploración e Investigación en Recursos Geotérmicos, Servicio Geológico Colombiano, Bogotá, Colombia.

(*)jbrueda@sgc.gov.co; jbrueda86@gmail.com 


\section{INTRODUCCIÓN}

En el marco de las labores de campo en el sector de San Diego, Municipio de Samaná, adelantados por el Servicio Geológico Colombiano (SGC), relacionadas a la exploración e investigación de los recursos geotérmicos en el territorio nacional, fueron caracterizadas las unidades aflorantes de este sector, permitiendo adelantar la caracterización geoquímica, petrográfica (mineralogía y caracterización de alteraciones) y geocronológica (dataciones U-Pb y Ar-Ar) de los cuerpos intrusivos plutónicos, subvolcánicos y volcánicos, dentro del área geotérmica de San Diego.

Trabajos anteriores como el de Feininger et al. (1972) son la base de la cartografía del área y del reconociendo de basamento metamórfico (Complejo Cajamarca), los cuerpos intrusivos y la única unidad sedimentaria que aflora en la zona de estudio (FIGURA 1). Otros trabajos tuvieron como objetivo el reconocimiento y la caracterización de los volcanes de la zona y sus depósitos asociados. Trabajos como el de Toro (1989, 1991) hace la primera caracterización del Volcán de San Diego y Florez (1987) quien caracteriza uno de los depósitos de esta zona. Más adelante Monsalve y Ortíz (2013), Monsalve et al. (2014, 2017) y Monsalve (2015), caracterizan las unidades eruptivas del mismo volcán de San Diego y del recién descubierto volcán El Escondido.

Los primeros indicios de actividad geotérmica en San Diego son reflejados por las manifestaciones hidrotermales registradas en superficie y que fueron en principio referenciadas en el desarrollo del Proyecto de Investigación Geotérmica en la región del Macizo Volcánico del Ruiz (CHEC, 1968). Nuevamente CHEC (1981) hace referencia a una anomalía térmica relacionada con actividad volcánica con productos que llaman pórfidos en el área de San Diego.

La actividad termal de la zona ha sido en principio referenciada por parte de CORPOCALDAS, pero ya hoy en día, se tiene reporte de 15 manifestaciones termales, nueve en cercanías a focos volcánicos reconocidos y seis en el costado occidental de la zona de estudio, sector Puente Linda (SGC, 2013).

La presencia de volcanismo reciente (fuente de calor), cuerpos porfiríticos que por sus características sugieren un emplazamiento muy cercano a la superficie con edades pleistocenas, además de la alteración hidrotermal al occidente del área y cuerpos controlados por fallas y fracturamiento (debilidad del subsuelo), hacen necesaria la caracterización a detalle de estas unidades que junto a la evidencia que estas características proporcionan y el análisis de las fuentes termales, posicionan la zona de trabajo como de interés para la exploración de recursos geotérmicos.

\section{LOCALIZACIÓN Y CONTEXTO GEOLÓGICO}

El área geotérmica de San Diego abarca un área de 460 $\mathrm{km}^{2}$, localizada en el municipio de Samaná, Caldas, compartiendo el extremo occidental con el Corregimiento de Puente Linda, Departamento de Antioquia y al este con el Municipio de Norcasia; geográficamente está localizado en el flanco oriental de la Cordillera Central de Colombia entre las latitudes $5^{\circ} 44^{\prime}$ y $5^{\circ} 29^{\prime} \mathrm{N}$ y longitudes 7509' y 7453', y hace parte del extremo norte de la franja de volcanes de esta cordillera. El área cubre las planchas cartográficas en escalas 1:25.000 168IIIB (IGAC, 1979), 188IA, 188IB, 188IC, 188ID (IGAC, 1961) y 188IIIA, 188-IIIB (FIGURA 1).

La geología está dominada por el Complejo Cajamarca con predominio de esquistos alumínicos, cuarcitas, esquistos verdes y en menor proporción anfibolitas (Feininger et al., 1972). La única unidad sedimentaria corresponde al horizonte fosilífero de Berlín de edad cretácea (Albiano) (Etayo, en Rueda y Rodríguez, 2016) compuesta por shales, areniscas, conglomerados y limolitas calcáreas. Esta unidad ha sido objeto de exploración de uranio por parte de la compañía $\mathrm{U}_{3} \mathrm{O}_{8}$ Corp. y casos de estudios más detallados en Pimiento (2011) quien caracteriza la mineralogía del uranio y algunos elementos menores económicamente explotables, Ríos-Guerrero (2012) quien analiza la estratigrafía y Caceres (2012) quien describe a detalle el origen de las concentraciones anómalas de uranio, así como vanadio, molibdeno, fosforo y zinc.

Cuatro grandes cuerpos ígneos intruyen el basamento metamórfico del Complejo Cajamarca: el Stock de Florencia (Tcdf) de edad paleógena, el Batolito de Sonsón (KTcds) de edad Cretácico superior descrito en González (2002), la Alaskita de Samaná (Kas) y el Complejo Ígneo de Samaná (Kds) los dos de edad Cretácea.Trabajos como eldeLoaiza(2012)caracterizan la totalidad de esta última unidad. Además, aflora un cuerpo intrusivo foliado denominado "Intrusivo Gnéisico de Naranjales" (TRin) caracterizados como cuerpos intrusivos néisicos sintectónicos (Feininger et al., 1972; González, 1990; Vinasco et al., 2006; López et al., 2007), de edad triásica (Vinasco et al., 2006), pero cuyo conocimiento geocronológico es limitado. 
La actividad magmática pleistocena está representada por pequeños y numerosas intrusiones hipoabisales de naturaleza andesítica-dacítica y dacítica (Feininger et al., 1972). El vulcanismo reciente está asociado a los volcanes de San Diego (Florez, 1987; Toro, 1989, 1991; Monsalve y Ortíz, 2013) y El Escondido (Monsalve y Ortíz, 2013; Monsalve et al., 2017), constituyéndose en el volcanismo más reciente del extremo norte de los Andes Colombianos.
Estructuralmente la zona está dominada por la falla Palestina (Feininger, 1970), que atraviesa el centro de la zona en dirección NNE-SSW, junto a fallas paralelas como la falla Patio Bonito y la falla San Diego (Page, 1986). La falla Rio Dulce propuesta por González (1980) para la plancha 187, está dada por el trazo del rio Samaná a la altura del sector de Puente Linda.

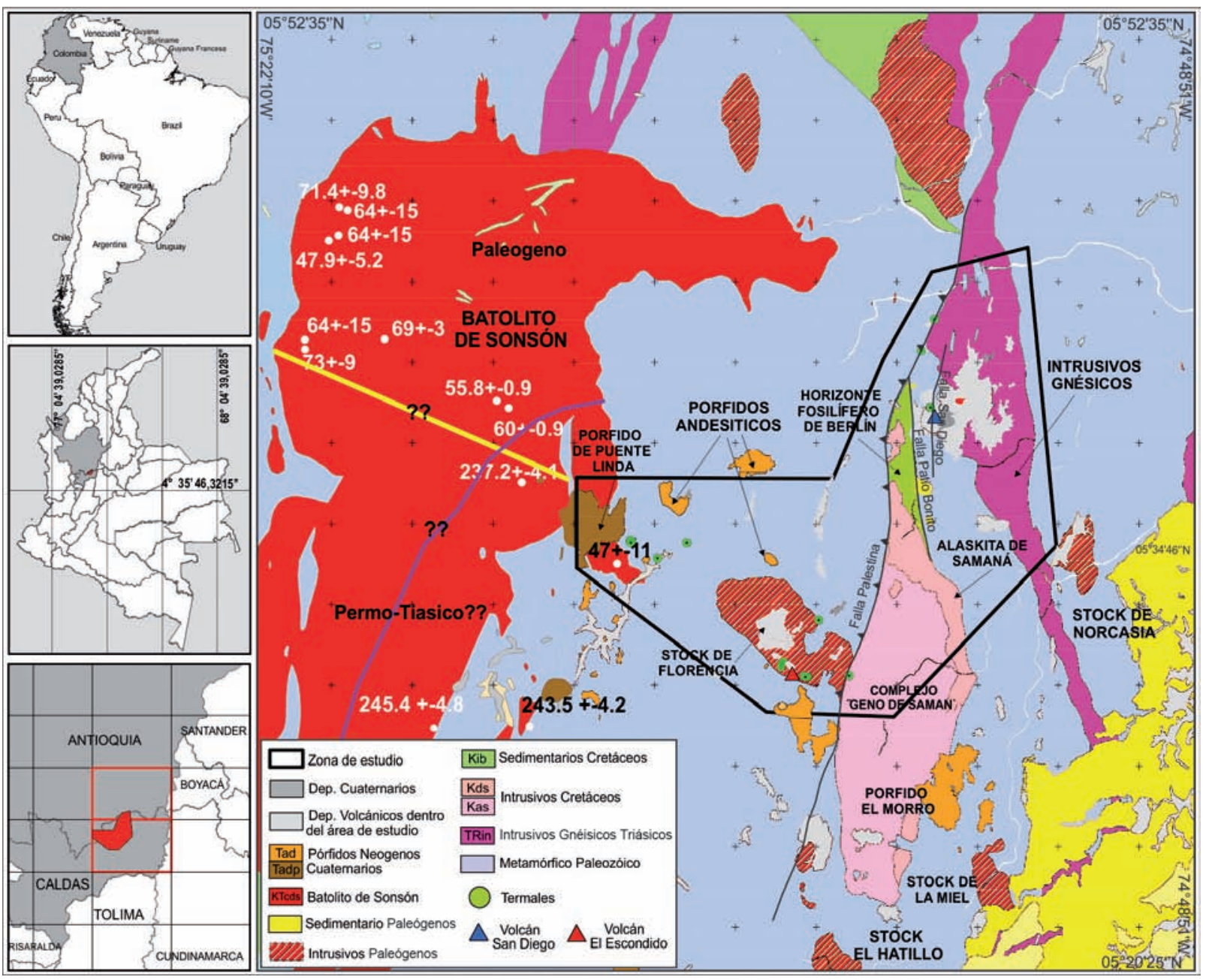

FIGURA 1. Ubicación, dataciones y geología del área de estudio. Fallas mostradas solo dentro del área de estudio (Feininger, 1970; Page, 1986). Geología editada de Barrero y Vesga (1976), González et al. (1980a, 1980b), Feininger et al. (1972) y Rueda y Rodríguez (2016). La línea amarilla representa un límite inferido separando el Batolito de Sonsón en eventos Permo-Triásico al sur y Paleógeno al norte en Leal-Mejía (2011). La línea azul casi vertical representa el límite inferido en el mapa geológico escala 1:1.000.000 de Gómez et al. (2015b) donde al este se representa las edades más antiguas y al oeste y arriba de la línea azul se representan las edades Paleógenas. Dataciones fuera del área de estudio tomadas de Gómez et al. (2015a).

\section{METODOLOGÍA}

Los recorridos para el mapeo del área se realizaron partiendo de la información cartográfica de las memorias explicativas, realizadas por Feininger et al. (1972) para la plancha 188, La Dorada y 168,
Argelia y, de la información de los mapas geológicos de las mismas planchas (Barrero y Vesga 1976; Feininger et al., 1970). Para esto, tanto las estaciones como las muestras colectadas en ese trabajo fueron georreferenciadas planeando así nuevos recorridos y mayor detalle en la cartografía. Aunque cuerpos nuevos 
fueron reconocidos, los contactos de las unidades ya descritas en su momento no sufrieron cambios considerables, especialmente para el complejo de rocas metamórficas.

\section{Análisis químicos (ICP-MS, FRX y DRX) y dataciones U-Pb (LA-ICP-MS) y Ar-Ar}

Un total de 56 muestras de roca de origen intrusivo y volcánico fueron enviadas a los laboratorios del SGC. Cada muestra fue en principio molida mediante una trituradora de mandíbula y posteriormente pulverizada con un molino de tungsteno hasta llegar a un tamaño tamiz malla 200. Un peso aproximado de 100 gr del producto de esta preparación fue rotulado y entregados a los laboratorios químicos del SGC para su posterior análisis.

La caracterización de los elementos mayores se hizo mediante fluorescencia de rayos X (FRX) a 38 muestras con un equipo PANalytical AXIOS Minerals, para esto fueron pesados $10 \mathrm{~g}$ de muestra a la que posteriormente se le agregó un aglomerante, se homogenizó y se llevó al equipo prensador para formar la pastilla que posteriormente es analizada. Los resultados reportados se expresan en \%wt para cada uno de los elementos mayores $\left(\mathrm{SiO}_{2}, \mathrm{Al}_{2} \mathrm{O}_{3}, \mathrm{Na}_{2} \mathrm{O}, \mathrm{K}_{2} \mathrm{O}, \mathrm{P}_{2} \mathrm{O}_{5}, \mathrm{CaO}, \mathrm{MgO}\right.$, $\mathrm{TiO}_{2}, \mathrm{Fe}_{2} \mathrm{O}_{3}$, y FeO) incluyendo el LOI, exceptuando el manganeso que es presentado en ppm.

Para conocer la química de los elementos, menores y traza se empleó la técnica ICP-MS (Inductively Coupled Plasma-MassSpectrometry) la cual se hizo con un Espectrómetro de Masas con Plasma de Acoplamiento Inductivo con celda de colisión KED, Marca Perkin Elmer REF. NexION 300D. Para el análisis fueron separados $0,1 \mathrm{~g}$ de muestra haciendo la digestión con ácido clorhídrico, nítrico y perclórico para posteriormente llevar a volumen de $10 \mathrm{ml}$ con solución de ácido nítrico diluido al 3\% v/v. Los resultados son presentados en ppm.

Para la caracterización de las fases cristalinas de 35 muestras se utilizó la técnica de difracción de rayos $\mathrm{X}$ (DRX) con un equipo X-PERT PRO sin monocromador con fuente de rayos $\mathrm{X}$ de $\mathrm{Cu}$. Los resultados recibidos son cualitativos y semicuantitativos y no reportan minerales amorfos, por lo que el $100 \%$ de la muestra es presentada como cristalina. Por otro lado, la técnica se hizo en polvo desorientado, haciendo difícil la identificación de minerales arcillosos.
Los circones de las seis muestras que se dataron mediante $\mathrm{U}-\mathrm{Pb}$ fueron separados teniendo en cuenta el procedimiento de separación del laboratorio de huellas de fisión del SGC (Peña-Ureña et al., 2018). El proceso de datación fue hecho en las instalaciones del SGC sede CAN a cargo del Grupo de Tecnologías Nucleares mediante un espectrómetro de masas (ICPMS) Thermo Element 2 monocolector acoplado a un sistema Laser Photon Machine de 193 nm. Mediante imágenes de catodoluminiscencia, se ubicaron los puntos para su posterior ablación de acuerdo a las estructuras de cada circón. Las condiciones analíticas fueron: una energía al 55\%, un diámetro de ablación de 20 micras, tiempo de ablación de 1:05 minutos. El software para el análisis fue Isoplot 3.5.

Tres muestras fueron datadas mediante Ar-Ar en los laboratorios de la universidad del Estado de Oregon, USA. La técnica se hizo con un espectrómetro de masas ARGUS-VI usando el método de calentamiento gradual. Para el caso de las muestras de este trabajo, donde las rocas tenían una edad tentativa menor a $2 \mathrm{Ma}$, se hizo una irradiación de 0,5 horas en el reactor TRIGA CLICIT de la Universidad del Estado de Oregon.

\section{RESULTADOS}

\section{Geología local}

Las rocas más antiguas que afloran en el área corresponden al basamento metamórfico de esa parte de la Cordillera Central agrupadas en el denominado Complejo Cajamarca (Feininger et al., 1972). Estas rocas se constituyen, en la zona de estudio, de esquistos alumínicos, esquistos verdes dispuestos como lentes de metros hasta kilómetros a lo largo de la foliación dominante (N-S) y esquistos grafitosos localizados en el costado occidental, filitas, cuarcitas aflorantes en el costado central y sur del área y anfibolitas distribuidas al norte del área.

La unidad TRin corresponde a un cuerpo de composición granítica con posterior metamorfismo conocido como Intrusivo Gnéisico por Feininger et al. (1972) o como intrusivos miloníticos, gneises sintectónicos entre otros términos. Esta unidad corta el costado oriental del área de estudio en dirección casi $\mathrm{N}-\mathrm{S}$; en numerosos afloramientos luce como una roca intrusiva de textura masiva de tamaño de grano medio a fino (FIGURA 2A y 2C), aunque al norte del área, en cercanías al rio Samaná la textura metamórfica se hace 
más evidente con una clara foliación y porfidoblastos de plagioclasas (FIGURA 2B), a simple vista luce cuarzo, plagioclasa, biotitas y granate.

Cuatro cuerpos plutónicos hacen parte de la geología del área de estudio, entre los que están el Complejo Ígneo de Samaná (Kds) y la Alaskita de Samaná (Kas) que aunque son mapeadas por separado, es común encontrar afloramientos leucocráticos dentro del Complejo Ígneo de Samaná; el complejo ígneo presenta diferentes litologías, predominan granodioritas, monzogranitos y en menor proporción cuerpos básicos a manera de pequeños diques (FIGURA 2C, 2D, 2E y 2F). Esta litología es vista solo en el área de trabajo, pero registros como en Loaiza (2012) referencia que al menos el 60\% del cuerpo es de litología dioríticagabroica.

La unida Alaskita (Kas) se muestra siempre muy meteorizada, en muestra de mano son visibles cristales de feldespatos, cuarzos y algunas biotitas oxidadas (FIGURA $2 \mathrm{G})$. Está en contacto fallado con la secuencia metamórfica al occidente y la unidad sedimentaria al oriente.
Afloramientos muestran el carácter intrusivo de cuerpos ácidos en la unida sedimentaria Kib, pero estos se tratarían de las intrusiones dacíticas (Td) y no del leucogranito, igualmente ningún evento térmico se observa en la unidad sedimentaria que suprayace la intrusión.

Afloran también el Stock de Florencia (Tcdf) y parte del Batolito de Sonsón (KTcds) los cuales presentan características muy similares, aunque el primero presenta un tamaño de grano más grande (FIGURA 2I y 2H). El Batolito (KTcds) está en contacto con el pórfido de Puente Linda (Tadp) y muestra una extensa e intensa alteración que dificulta su diferenciación. Las dos unidades atraviesan el basamento metamórfico, tanto a cuarcitas como esquistos alumínicos, pero solo se evidenció un ligero metamorfismo de contacto entre el Stock y la unidad metamórfica de cuarcitas; esta misma unidad Tcdf, sirve igualmente de basamento a las intrusiones dómicas del complejo de domos del volcán El Escondido, y claramente al propio cráter del volcán, evidenciado en numerosos fragmentos angulares de granodioritas dentro de la mayoría de los depósitos volcánicos.
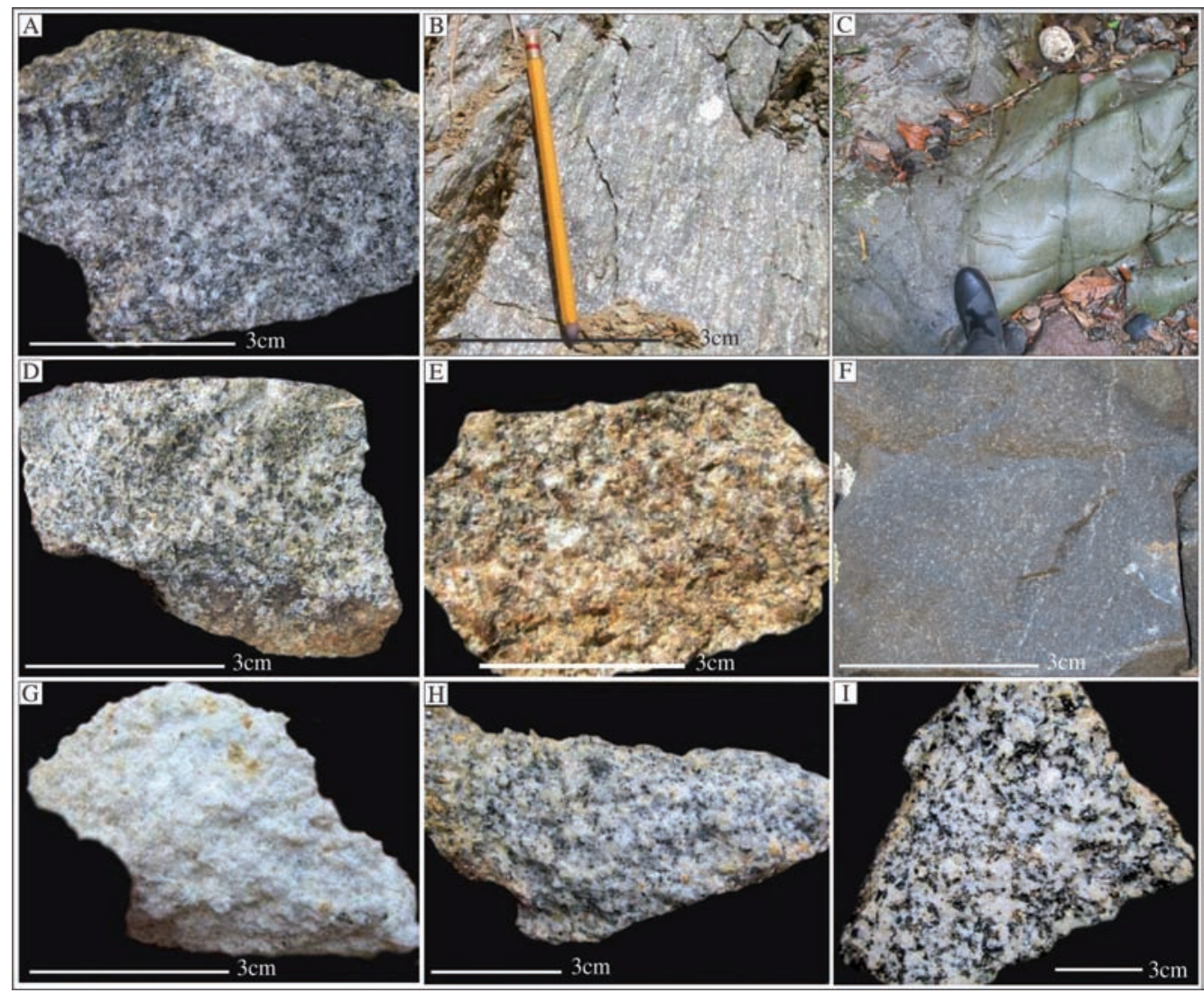

FIGURA 2. Muestras de mano de las unidades intrusivas aflorantes. A. Intrusivo Gnéisico (TRin) con textura ígnea. B. Intrusivo Gnéisico de Samaná con textura gnéisica y augen de plagioclasa. C. Diques máficos en la unidad TRin. D. E. y F. Complejo Ígneo de Samaná (Kds). G. Alaskita o leucogranito de Samaná (Kas). H. Batolito de Sonsón (KTcds). I. Granodiorita del Stock de Florencia (Tcdf). 
Al menos 4 cuerpos porfiríticos dacíticos (Td) se encuentran en el área de estudio, dos de ellos reconocidos en Feininger et al. (1972). Se presentan comúnmente alterados (matriz y fenocristales poco reconocibles), color blanco con fenocristales de cuarzo y asociados geográficamente a la falla Palestina en el contacto entre el complejo metamórfico y la unidad sedimentaria "Horizonte Fosilífero de Berlín (Kib)".

Un total nueve cuerpos porfiríticos de tamaños no mayores a $3 \mathrm{~km}^{2}$ de los cuales cuatro fueron reconocidos en Feininger et al. (1972) y llamados pórfidos andesíticos-hornblendíticos (Tad) se encuentran en el área de estudio. En muestra de mano presentan grandes fenocristales blancos de plagioclasa euhedrales de hasta $2 \mathrm{~cm}$ y algunos más pequeños de hornblenda, la matriz es de color gris y varia la relación matriz fenocristales. La mayor diferencia entre ellos radica en el tamaño de los fenocristales de plagioclasa (de $2 \mathrm{~mm}$ a casi $1 \mathrm{~cm}$ ) y de los anfíboles (menos de $1 \mathrm{~mm}$ hasta casi $6 \mathrm{~mm}$ ) (FIGURA 3B, 3C y 3E). Están comúnmente alterados pasando a ser de color amarillento y blanco, y en ocasiones con una matriz endurecida (FIGURA $3 \mathrm{E}$ y $3 \mathrm{~F}$ ) o muy fácil de disgregar (FIGURA $3 \mathrm{H}$ ).

Dentro de este grupo Tad es catalogado según Feininger et al. (1972) el cuerpo dómico del Maar de San Diego el cual no es claramente hornblendítico sino más bien biotítico con un carácter más dacítico (FIGURA 3J y $3 \mathrm{~K}$ ). Igualmente el complejo de domos del volcán El Escondido de Florencia presenta un aspecto muy similar a los demás cuerpo porfiríticos pero estos son claramente más recientes y correspondería a la actividad intracaldérica del volcán (Monsalve, 2015; Monsalve et al., 2017) (FIGURA 3L y 3M).

Excluyendo los cuerpos dómicos relacionados a las dos estructuras volcánicas, algunas de las demás litologías porfiríticas del grupo Tad presentan relieves elevados con geoformas dómicas (FIGURA 3A, 3G y 3I) sugiriendo una intrusión que llegó a la superficie, lo cual se ve reflejado también en la petrografía, donde se observan las matrices muy vítreas.

En cercanías al volcán El Escondido en dirección sur, una estructura cilíndrica resalta de la topografía cubierta por vegetación alta del Parque Natural Selva de Florencia (PNNSF). En la FIGURA 3N se observa una pared inclinada casi $90^{\circ}$, justo en ese punto la roca que se observó es una brecha con líticos porfiríticos y algunos otros metamórficos (FIGURA 3O). Antes de llegar a ese punto, solo se controlan rodados de roca porfirítica (FIGURA 3P) y casi ningún afloramiento es visible, pero es claro que se trata de un cuerpo de naturaleza intrusiva. Por su forma, textura y debido la actividad volcánica de la zona, pero sin tener un estricto control de campo más al sur de dicha geoforma y dados los escasos afloramientos, se plantea que se trate de una diatrema.

\section{Petrografía}

La unidad Intrusivo Gnéisico muestra variación composicional entre granitos (monzogranitos), granodioritas y tonalitas, pueden tener estructura foliada con porfidoblastos de plagioclasa alterada (FIGURA 4A). Predomina el cuarzo con 24 a 45\%, seguido de plagioclasa entre 16 y 47\%, y cantidades variables de feldespato potásico entre 5 y $38 \%$, biotita 2 y $15 \%$ con trazas de granate, piroxenos y minerales de alteración como sericita y clorita (FIGURA 4B).

La unidad Complejo de Samaná claramente muestra variación composicional y mineralógica con litologías félsicas de granodioritas-monzogranitos con cuarzo entre 35 y 50\%, plagioclasa entre 17 y $35 \%$ (generalmente tipo albita) y feldespato potásico entre 15 y 17\% (tipo sanidina). Las litologías gabrodioritas presentan cuarzo en un 2,3\%, plagioclasa entre 48 y $59 \%$ y anfíbol tipo hornblenda entre 22 y $36 \%$ con cantidades variables de sericita $<20 \%$ y minerales opacos (FIGURA 4C y 4D). En la unidad Alaskita de Samaná predominan los granitos leucocráticos con feldespato potásico con $34,3 \%$, plagioclasa $26 \%$ y cuarzo 24,3\%, comúnmente alteradas a sericita y cantidades variables de biotita (FIGURA 4E).

En el Stock de Florencia predominan las granodioritas, cuarzodioritas y tonalitas de grano medio a grueso con plagioclasa tipo albita principalmente entre 45 y $62 \%$, cuarzo entre 16 y $37 \%$, feldespato potásico entre 1,7 y $13 \%$, biotita entre 4 y $13 \%$ y trazas de anfíboles tipo hornblenda, sericita y clorita (FIGURA 4F). Para el Batolito de Sonsón en la zona de estudio, se observó predominancia de granodioritas de grano fino con plagioclasa en un $35,6 \%$, cuarzo $34 \%$, feldespato potásico con $16 \%$ y biotita $9,6 \%$ con variación en el contenido de anfíbol, clorita y sericita (FIGURA 4G).

Los cuerpos subvolcánicos son de composición andesítica y dacítica. Las andesitas tienen fenocristales $(>2 \mathrm{~mm})$ y microfenocristales $(2-0,5 \mathrm{~mm})$ de plagioclasas (predominio de albita y labradorita mediante análisis por DRX) microfenocristales de anfíboles hexagonales y cuarzo bipiramidal; la matriz varía de microcristalina a criptocristalina, con microcristales de anfíbol, con porcentajes entre 50 y 90\%, en algunas rocas la matriz 
vítrea predomina sobre la cristalina (FIGURA 4J y $4 \mathrm{~K})$. Las dacitas tienen microfenocristales de cuarzo bipiramidal (FIGURA 4H) entre 6 y 10\%, en menor proporción de plagioclasa entre 4 y $7 \%$ y hornblenda puede estar presente. La matriz de estos cuerpos varía de $51 \%$ a $80 \%$ y comúnmente se muestra alterada.
El pórfido de Puente Linda tiene matriz microlítica con fenocristales y microfenocristales de plagioclasa entre $5,8-13,8 \%$ y presenta relleno de carbonatos en fracturas, cuarzo puede estar presente en $(0,5-5,6 \%)$, hornblenda entre $0,31-3,2 \%$ parcialmente absorbida por la matriz o alterada a carbonatos (FIGURA 5C).

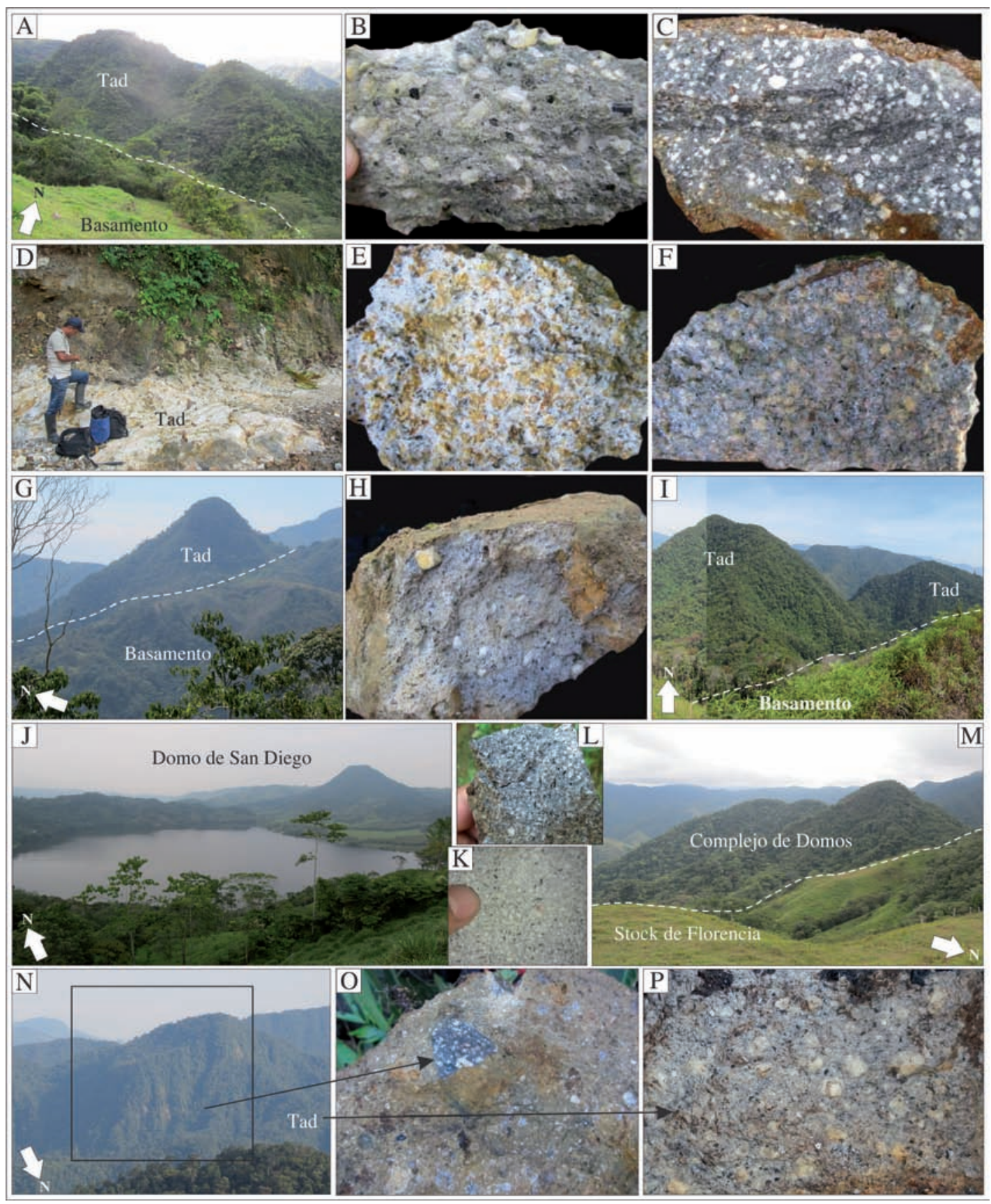

FIGURA 3. Aspecto de las unidades subvolcánicas (Tad) y volcánicas. A. y B. Cuerpo del sector noroccidental del área de estudio. C. D. E. F. Muestra de mano y afloramientos de los cuerpos porfiríticos alterados en el sector de Puente Linda a lo largo del Rio Samaná. G. H. I. Afloramiento y muestra de mano de los cuerpos porfiríticos en sector de la Quiebra. J. K. Panorámica del domo de San Diego y detalle de la roca. L. M. Panorámica del complejo de domo del volcán Escondido (Florencia) y detalle de la roca. N. y O. Panorámica de la diatrema y detalle de muestra de mano. P. Detalle de la roca alrededor de la diatrema. 
El domo de San Diego es dacítico con presencia de fenocristales de plagioclasa y en menor proporción microfenocristales y microcristales de cuarzo anhedral entre 6-8\%, biotita tabular rojiza y parda entre 15 y 25\% y plagioclasa subhedral que varía entre 6 y 10\% (FIGURA 4N) dentro de una matriz criptocristalina félsica. Según DRX las fases de feldespato reportadas para este cuerpo son sanidina y anortita.

El complejo de domos del volcán El Escondido es andesítico con fenocristales y microfenocristales de hornblenda euhedrales hexagonales (FIGURA 4M) (magnesohormblenda identificada por DRX) y plagioclasa subhedral según DRX tipo albita y en menor proporción andesina, con microcristales de piroxenos siendo rodeados por microcristales de hornblendas (FIGURA 4L). La matriz es microcristalina y vítrea para algunos de los líticos dentro de los depósitos de origen volcánico.

La geoforma cilíndrica al sur (¿Diatrema?) microscópicamente muestra líticos entre 0,1 y mayores a $1,5 \mathrm{~mm}$ de roca porfirítica andesítica con cristales angulares de plagioclasa y anfíboles, el otro grupo de líticos son metamórficos con composiciones cuarzosas y algunos otros esquistosos con evidente foliación superando algunos los $3 \mathrm{~cm}$ (FIGURA 4O). También son visibles cristales libres comúnmente de plagioclasas con formas bien definida y algunos anfíboles, todo esto dentro de una matriz criptocristalina de color marrón que no supera el $40 \%$ de la roca.

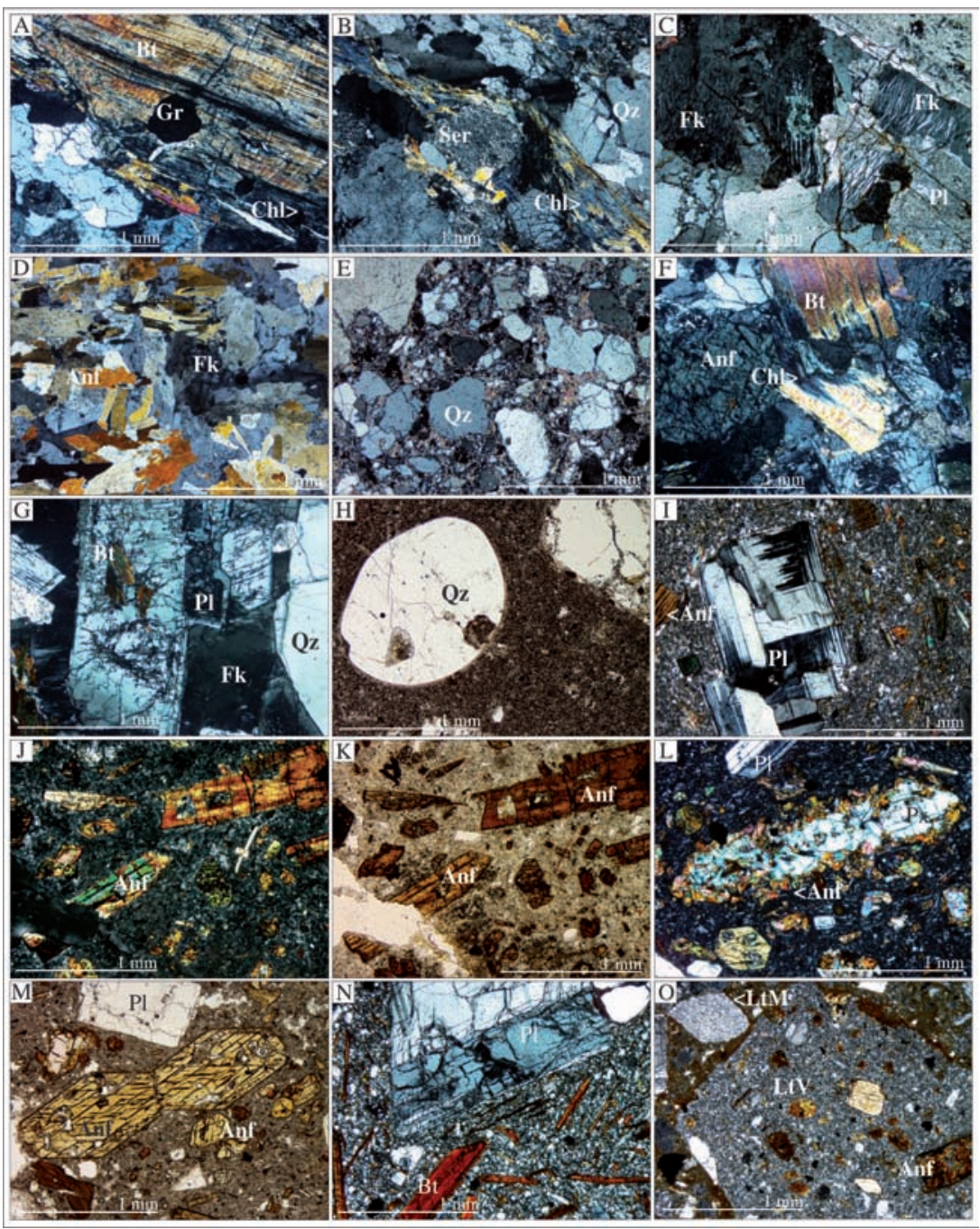

FIGURA 4. Microfotografías cuerpos plutónicos, hipoabisales y volcánicos. A. y B. Unidad TRin con clorita (Chl), granate (Gr) y sericita (Ser). C. Unidad Complejo de Samaná, facie granítica. D. Unidad Complejo de Samaná, facie diorítica-gabroica. E. Alaskita de Samaná. F. Unidad Stock de Florencia. G. Batolito de Sonsón. H. Pórfidos dacíticos con cuarzo bipiramidal. I. Cuerpos andesiticos. J. K. Cuerpo andesítico con matriz vítrea. L. M. Domo de El Escondido con plagioclasa (P1) y Anfíbol (Anf) tipo hornblenda principalmente y piroxeno (Px). N. Domo volcán San Diego con Qz, Pl y Bt en matriz microcristalina de Qz. O. Brecha al sur del área de estudio (LtV: Lítico volcánico. LtM: Lítico metamórfico). 


\section{Alteraciones}

Gran parte del área de estudio esta demarcada por una intensa meteorización de las unidades aflorantes, predominando la oxidación de la unidad ígnea (TRin) y esquistos sericíticos (TRes) y unidades saprolizadas en el caso del Stock de Florencia (Tcdf) y Batolito de Sonsón (KTcds). Los esquistos en todas sus variedades presentan pequeños sectores con alteraciones que hacen cambiar el color de la roca, y cuyas extensiones varían desde pocos metros a cientos. Los cuerpos de composición acida presentan una coloración blanca de textura arenosa y los intermedios-ácidos (Tad) se muestra mayormente alterados con textura arcillosa de color naranja. En el sector norte se muestra una meteorización fuerte en la unidad gnéisica en la mayoría de su extensión y alteraciones con presencia de clorita y sericita. En el sector donde aflora en mayor extensión el Complejo Ígneo de Samaná (Kds), el leucogranito (Kas) y esquistos sericíticos con lentes de esquistos verdes (TRev) presenta una apariencia alterada superficialmente, especialmente para el cuerpo alaskítico que por su composición ácida y por el intemperismo se muestra siempre fácil de disgregar. Las manifestaciones de alteración hipógena más notorias se localizan en el sector de Puente Linda. Esta alteración se ve igualmente en el Batolito de Sonsón en el contacto con el cuerpo de Puente Linda donde en muestra de mano la roca luce muy arcillosa, pero con evidencias del carácter granítico de la roca. Dentro del propio cuerpo porfirítico Tadp, se ven sectores de alteración argílica y fílica con una marcada mineralización de sulfuros por zonas. Este cuerpo presenta sectores controlados estructuralmente con intensa alteración y brechas presentando una alteración sericita+cuarzo+pirita. Los tipos de alteración más común se resumen en la TABLA 1 y se ilustran en la FIGURA 5.

TABLA 1. Resumen de las alteraciones y resultados de difracción de rayos X para algunas de las muestras del área de estudio, especialmente en el sector de Puente Linda (Qz: Cuarzo. Ser: Sericita. Dck: Dickita. Ill: Illita. Cb: Carbonato. K: Caolinita. Ch: Clorita).

\begin{tabular}{|c|c|c|c|c|c|c|}
\hline Cuerpo & \multicolumn{3}{|c|}{ Ubicación } & Fase minerales (Fílica) & \multirow{2}{*}{\multicolumn{2}{|c|}{ Fase minerales (Argílica) }} \\
\hline Tadp & \multicolumn{3}{|l|}{ Puente Linda } & $\mathrm{Qz}+\mathrm{Ser}+\mathrm{Dck}+\mathrm{Cb}$ & & \\
\hline Tadp & \multicolumn{3}{|c|}{ Puente Linda } & $\mathrm{Qz}+\mathrm{Ser}+\mathrm{Cb}$ & \multicolumn{2}{|c|}{$\mathrm{Ser}+\mathrm{Qz}+\mathrm{Cb}$} \\
\hline Tad & \multicolumn{3}{|c|}{ Sector Puente Linda Hacienda la Circasia } & $\mathrm{Qz}+\mathrm{Dik} \pm \mathrm{K}$ & \multicolumn{2}{|c|}{--- } \\
\hline Tad & \multicolumn{3}{|c|}{ Sector norte de Puente Linda } & $\mathrm{Qz}+\mathrm{K}$ & \multicolumn{2}{|c|}{$\mathrm{Qz}+\mathrm{K}$} \\
\hline Tad & \multicolumn{3}{|c|}{ Vía Puente Linda - Nariño } & $\mathrm{Qz}+\mathrm{Ser}$ & \multicolumn{2}{|c|}{--} \\
\hline Tad & \multicolumn{3}{|c|}{ Sector La Quiebra } & --- & \multicolumn{2}{|c|}{$\mathrm{Qz}+\mathrm{K}$} \\
\hline Tad & \multicolumn{3}{|c|}{ Sector Puente Linda, al oeste del río Samaná } & --- & \multicolumn{2}{|c|}{$\mathrm{Qz}+\mathrm{K}+\mathrm{Dck}$} \\
\hline Tadp & \multicolumn{3}{|l|}{ Puente Linda } & --- & \multicolumn{2}{|c|}{$\mathrm{Qz}+\mathrm{K}+\mathrm{Ill}$} \\
\hline \multirow{5}{*}{\multicolumn{2}{|c|}{ Muestra-ubicaión }} & Fase & Porcentaje & Muestra-ubicaión & Fase & Porcentaje \\
\hline & & $\operatorname{Microclina}(\mathrm{K}, \mathrm{Na})$ & 50,5 & & Cuarzo & 55,6 \\
\hline & & Cuarzo & 35,9 & & Labradorita & 14,7 \\
\hline & & Moscovita & 12,3 & & Caolinita & 29,3 \\
\hline & & Jarosita & $<2,0$ & & Zeolita A & $<2,0$ \\
\hline & & Cuarzo & 68,4 & & Cristobalita & 28,0 \\
\hline & & Dickita & 11,9 & & Tenorita & No cuantificable \\
\hline & & Caolinita & 17,6 & & Halloysita-7A & No cuantificable \\
\hline & & Cristobalita & $<2,0$ & & Caolinita & 71,9 \\
\hline & & Kesterita & $<2,0$ & & Goethita & $<2,0$ \\
\hline & & Jacobsita & $<2,0$ & & Magnesioferrita & No cuantificable \\
\hline & & Cuarzo & 46,8 & & Moscovita & No cuantificable \\
\hline & & Sanidina $(\mathrm{K}, \mathrm{Na})$ & 15,7 & & Cuarzo & 46,8 \\
\hline & & Moscovita & 21,9 & & Sanidina & 15,7 \\
\hline & & Panunzita & $<2,0$ & & Moscovita & 21,9 \\
\hline & & Dickita & 3,7 & & Panunzita & $<2,0$ \\
\hline & & Ortoclasa & 11,8 & & Dickita & 3,7 \\
\hline & & Cuarzo & 61,3 & Via Puente Linda-Nariño & Ortoclasa & 11,8 \\
\hline & & Goethita & 7,5 & & Cuarzo & 53,4 \\
\hline & & Moscovita & 8,5 & & Sanidina & 27,5 \\
\hline & & Mereirerita & No cuantificable & & Caolinita & 3,8 \\
\hline & & Caolinita & No cuantificable & & Moscovita & 4,1 \\
\hline & & Ilita & 22,7 & & Dickita & 3,6 \\
\hline & & & & DSDJR-350-1-A & Ortoclasas & 7,7 \\
\hline
\end{tabular}


Cloritización y Seritización (débil): Reconocida por una evidente cloritización de micas y algunos anfíboles, mientras que la sericita ataca a los feldespatos sódicocálcicos y potásicos. Se presenta en los grandes intrusivos, especialmente en la unidad gnéisica. Los resultados de DRX reporta la facie moscovita que haría referencia tanto a la moscovita primaria que es evidente en sección delgada como a sericita, que es igualmente reconocible bajo el microscopio. Igualmente, la fase clinocloro es reconocida por DRX, el cual se trata de un mineral del grupo de las cloritas. Fílica (Sericítica): Afecta ligeramente a los grandes intrusivos (TRin, KTcds, Kds y Kas) reemplazando la plagioclasa por sericita y micas por cloritas, en ocasiones en sus núcleos o remplazándola totalmente como es el caso del intrusivo gnéisico. Se da mayormente en los cuerpos andesíticos en el sector de Puente Linda y en el propio pórfido de Puente Linda, donde altera los fenocristales y la matriz. Argílica: Representada por caolinita (K) y cuarzo (Qz) en los cuerpos porfiríticos y acompañada de sericita y dickita (Dck) reemplazando mayormente plagioclasa, también se presentan carbonatos (Cb) remplazando mayormente anfíboles y plagioclasa. Se expone en la mayoría de los cuerpos andesíticos y en el de Puente Linda, exceptuando el cuerpo al sur del área de estudio, el cual se muestra mucho menos alterado que los demás.
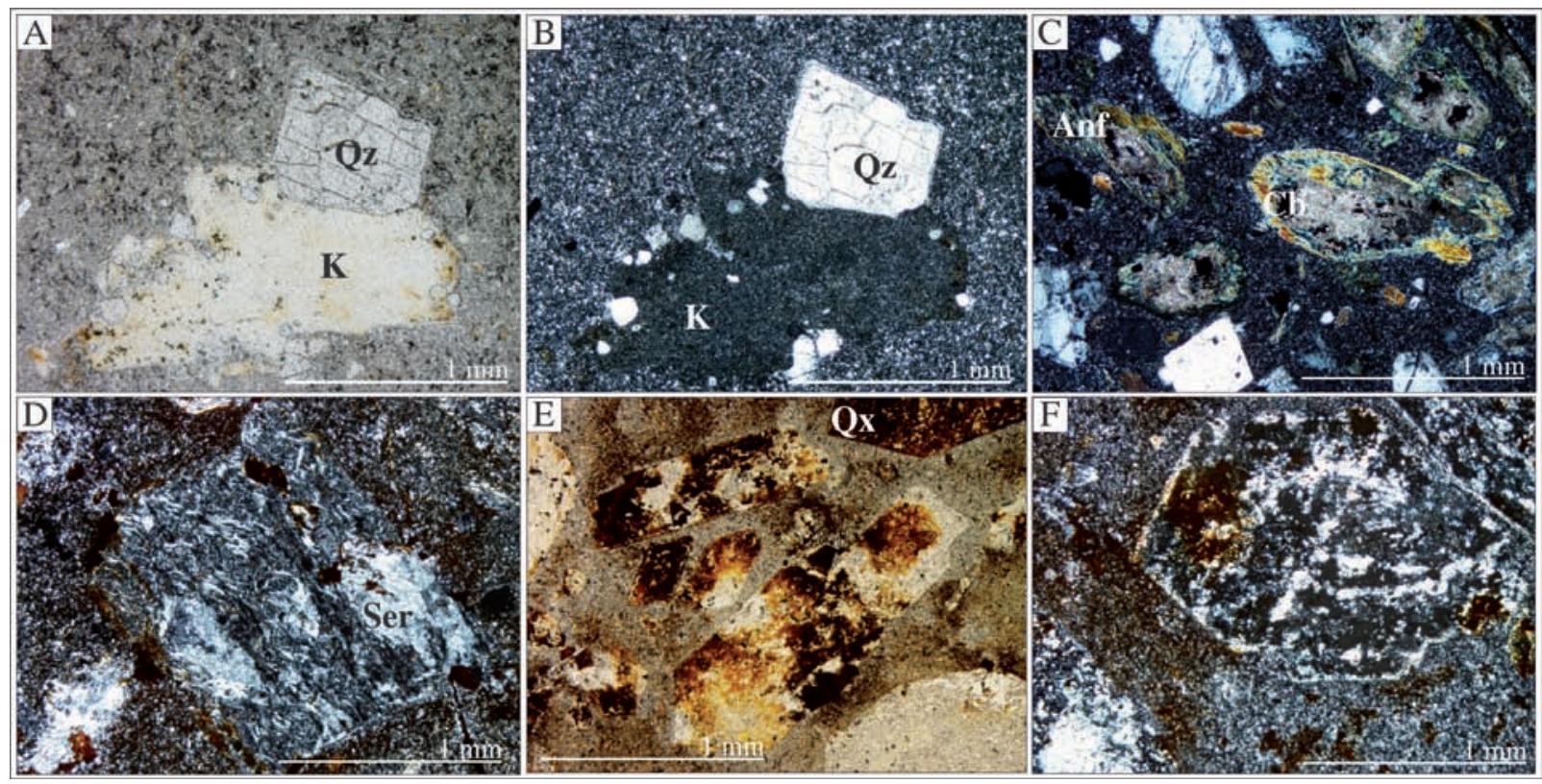

FIGURA 5. Microfotografía de algunas alteraciones en los cuerpos porfiríticos. A. y B. Pórfidos dacíticos con cuarzo y algunas plagioclasa y anfíboles, comúnmente alterados a caolinita (K). C. Cuerpos andesiticos (Tadp) con carbonatos (Cb) reemplazando anfíboles (Anf). D. E. F. Cuerpo andesítico con matriz vítrea, cristales oxidados y reemplazamiento de plagioclasa por sericita.

\section{Geoquímica}

Los resultados de geoquímica de roca total (TABLA 2 y 3) de los cuerpos plutónicos representados en 25 muestras dejan hacer las siguientes observaciones.

El cuerpo Intrusivo Gnéisico muestra una concentración de $\mathrm{SiO}_{2}$ que va desde 65,21 hasta 76,4 \%wt, los valores de $\mathrm{Al}_{2} \mathrm{O}_{3}$ van de aproximadamente de 12 a 13,5\%, el $\mathrm{K}_{2} \mathrm{O}$ va desde 2,2 a 2,79\%. Las variaciones del $\mathrm{CaO}$ son evidentes en estos cuerpos, tanto para lo muestreados en el área de estudio como los reportados en otros lugares, los valores tienen picos de 8 \%wt y bajos de menos de
$1 \%$ wt. El diagrama TAS clasifica las muestras como granitos y granodioritas (FIGURA 6A).

En la unidad Complejo Ígneo de Samaná los valores de $\mathrm{SiO}_{2}$ van de 68,15 a 74,18 \%wt para las muestras más acidas y el $\mathrm{Al}_{2} \mathrm{O}_{3}$ va de 14,02 a 18,14. Los contenidos de $\mathrm{Na}_{2} \mathrm{O}$ y K $\mathrm{K}_{2} \mathrm{O}$ están en el rango de 3,38 y 4,16 y entre 3,4 y 0,75 respectivamente y el $\mathrm{Ti}_{2} \mathrm{O}$ tiene cantidades de 0,34 a 1,98. Los valores de las muestras básicas muestran una variación importante en $\mathrm{SiO}_{2}$ con $53,13 \%$ wt y en $\mathrm{Na}_{2} \mathrm{O}$ y $\mathrm{K}_{2} \mathrm{O}$, con 4,1 y $0,74 \% w t$ respectivamente. $\mathrm{El} \mathrm{Ti}_{2} \mathrm{O}$ se presenta con 2,94 \%wt muy por encima que los valores de la roca caja (rocas 
acidas) al igual que el $\mathrm{Fe}_{2} \mathrm{O}_{3}$ con 13,721 \%wt. La clasificación TAS ubica las rocas del complejo ígneo en el campo de los gabros hasta los granitos, pasando por dioritas y cuarzodiorita (FIGURA 6A y 6B).

La unidad Alaskita de Samaná presenta valores de $\mathrm{SiO}_{2}$ entre 75,56 y 79,26\%wt, $\mathrm{Al}_{2} \mathrm{O}_{3}$ de 12 a $18 \%$ wt. El Na $2 \mathrm{O}$ $\mathrm{y} \mathrm{K}_{2} \mathrm{O}$ van de 2,56 a 3,37 y 1,56 a 5,08 respectivamente. Para el $\mathrm{CaO}$ se dan valores de 2,5 hasta por debajo del límite de detección, así como el MgO con valores menores a $0,2 \% w t$.

La unidad Stock de Florencia muestra valores de $\mathrm{SiO}_{2}$ entre 61,83 y 67,31 \%wt y 72,42 para una muestra, el
$\mathrm{Al}_{2} \mathrm{O}_{3}$ está entre el 16 y $20 \%$ wt, para el $\mathrm{Na}_{2} \mathrm{O}$ y el $\mathrm{K}_{2} \mathrm{O}$ no sobrepasan el 3,7 y 1,88 \%wt respectivamente, con un valor alto para la misma muestra (GR-246-1) de 0,2 de $\mathrm{Na}_{2} \mathrm{O}$ y $3,2 \%$ wt de $\mathrm{K}_{2} \mathrm{O}$. Según clasificación TAS las rocas se plotean en el campo de las granodioritas-diorita.

Las rocas del Batolito de Sonsón presentan contenidos de $\mathrm{SiO}_{2}$ que varían de 68,68 y 74,81 \%wt de la roca total, el $\mathrm{Al}_{2} \mathrm{O}_{3}$ tiene una variación de más de $5 \%$ wt entre la muestra con mayor y menor contenido de $\mathrm{Al}_{2} \mathrm{O}_{3}$. Para el $\mathrm{Na}_{2} \mathrm{O}$ los valores van de 3,09 a 3,62 y el $\mathrm{K}_{2} \mathrm{O}$ de 2,4 y $4,3 \%$ wt. $\mathrm{El} \mathrm{CaO}$ se mantiene casi constante con valores de 1,2 y $1,1 \%$ wt y se clasifican como rocas graníticas y cuarzodioríticas según diagrama TAS.

TABLA 2. Geoquímica de elementos mayores.

\begin{tabular}{|c|c|c|c|c|c|c|c|c|c|c|c|c|}
\hline \multicolumn{6}{|c|}{ Unidad TRin } & \multicolumn{5}{|c|}{ Unidad Kds } & \multicolumn{2}{|c|}{ Unidad Kas } \\
\hline Muestra & GR-80 & JR-026 & JR-137 & JR-067 & JR-124 & $\begin{array}{c}\text { SDGR- } \\
166 \\
\end{array}$ & JR-380 & GR-094 & $\begin{array}{c}\text { MAB- } \\
036 \\
\end{array}$ & JR-379 & JR-129-1 & JR-132-1 \\
\hline Longitud & $-74,9259$ & $-74,9303$ & $-74,9072$ & $-74,9194$ & $-74,9836$ & $-75,002$ & $-74,992$ & $-74,9854$ & $-74,9859$ & $-74,97$ & $-74,9729$ & $-74,9541$ \\
\hline Latitud & 5,6124 & 5,6591 & 5,5659 & 5,7124 & 5,527 & 5,50801 & 5,5309 & 5,48405 & 5,5444 & 5,5811 & 5,5771 & 5,5304 \\
\hline Elemento & $\% w t$ & $\%$ wt & $\% w t$ & $\% w t$ & $\% w t$ & $\% w t$ & \%wt & \%wt & $\%$ wt & \%wt & $\% w t$ & $\%$ wt \\
\hline $\mathrm{SiO}_{2}$ & 65,21 & 76,49 & 69,63 & 68,24 & 74,18 & 53,13 & 76,31 & 68,15 & 53,90 & 77,10 & 79,26 & 75,53 \\
\hline $\mathrm{TiO}_{2}$ & 0,85 & 0,36 & 1,28 & 0,90 & 0,35 & 1,73 & 0,23 & 0,97 & 2,98 & 0,10 & 0,07 & 0,29 \\
\hline $\mathrm{Al}_{2} \mathrm{O}_{3}$ & 12,96 & 13,18 & 10,74 & 15,59 & 14,64 & 18,14 & 14,02 & 15,33 & 14,27 & 14,12 & 12,52 & 21,26 \\
\hline $\mathrm{Fe}_{2} \mathrm{O}_{3}$ & 1,13 & 0,70 & 3,98 & 1,17 & 1,09 & 1,24 & 1 & 1,08 & 2,00 & 0,97 & 0,47 & 0,86 \\
\hline MgO & 3,03 & 1,75 & 3,74 & 2,26 & 0,85 & 5,03 & 0,15 & 1,84 & 3,29 & $<0,10$ & $<0,10$ & 0,16 \\
\hline $\mathrm{CaO}$ & 8,07 & 0,38 & 3,43 & 1,88 & 0,76 & 7,18 & 0,52 & 2,75 & 6,30 & $<0,10$ & $<0,10$ & $<0,10$ \\
\hline $\mathrm{Na}_{2} \mathrm{O}$ & 1,90 & 1,03 & 0,37 & 2,61 & 3,45 & 3,53 & 3,63 & 3,37 & 4,16 & 2,56 & 3,37 & $<0,10$ \\
\hline $\mathrm{K}_{2} \mathrm{O}$ & 2,26 & 2,79 & 2,07 & 3,10 & 3,40 & 1,03 & 3,59 & 2,20 & 0,75 & 5,08 & 4,27 & 1,56 \\
\hline $\mathbf{P}_{2} \mathbf{O}_{5}$ & 0,21 & 0,05 & 0,14 & 0,16 & 0,06 & 0,41 & 0,03 & 0,15 & 0,43 & $<0,024$ & $<0,024$ & $<0,024$ \\
\hline LOI & 1,56 & 2,16 & 5,31 & 2,01 & 1,89 & 2,51 & 1,33 & 1,12 & 1,09 & 1,69 & 0,7 & 6,64 \\
\hline FeO & 3,84 & 2,84 & 3,7 & 3,58 & 1,06 & 7,49 & 0,44 & 3,67 & 10,55 & $<0,13$ & $<0,13$ & 0,22 \\
\hline \multicolumn{8}{|c|}{ Unidad Tcdf } & \multicolumn{2}{|c|}{ Unidad KTcds } & \multicolumn{3}{|c|}{ Unidad Td } \\
\hline Muestra & JR-001 & JR-123 & GR-248 & $\begin{array}{c}\text { GR- } \\
246-1\end{array}$ & $\begin{array}{c}\text { GR- } \\
197-1\end{array}$ & $\begin{array}{c}\text { GR- } \\
194-1\end{array}$ & JR-333 & $\begin{array}{c}\text { MAB- } \\
111\end{array}$ & GR-083 & JR-393 & JR-398 & GR-334 \\
\hline Longitud & $-75,044$ & $-75,008$ & $-75,0606$ & $-75,0742$ & $-75,065$ & $-75,065$ & $-75,1342$ & $-75,1291$ & $-74,96141$ & $-74,9698$ & $-74,9629$ & $-74,9662$ \\
\hline Latitud & 5,521 & 5,5202 & 5,55139 & 5,5558 & 5,5375 & 5,5293 & 5,5638 & 5,5628 & 5,5948 & 5,668 & 5,5969 & 5,5888 \\
\hline Elemento & \%wt & $\% w t$ & $\% w t$ & $\% w t$ & $\% w t$ & $\%$ wt & $\% w t$ & $\% w t$ & $\% w t$ & $\% w t$ & $\% w t$ & $\% w t$ \\
\hline $\mathrm{SiO}_{2}$ & 65,80 & 67,31 & 65,77 & 72,42 & 61,83 & 66,36 & 74,81 & 68,68 & 80,04 & 79,82 & 84,28 & 71,32 \\
\hline $\mathrm{TiO}_{2}$ & 0,60 & 0,50 & 0,65 & 0,75 & 0,75 & 0,65 & 0,14 & 0,14 & 0,13 & 0,32 & 0,09 & 0,68 \\
\hline $\mathrm{Al}_{2} \mathrm{O}_{3}$ & 16,48 & 17,35 & 16,79 & 15,32 & 20,69 & 17,44 & 14,25 & 21,33 & 15,99 & 14,38 & 10,13 & 17,72 \\
\hline $\mathrm{Fe}_{2} \mathrm{O}_{3}$ & 1,02 & 1,35 & 1,55 & 1,36 & 3,44 & 3,09 & 0,28 & 0,62 & 1,12 & 1,12 & 0,63 & 4,17 \\
\hline MgO & 2,45 & 1,88 & 2,73 & 1,77 & 3,12 & 2,48 & 0,25 & 0,19 & 0,34 & 0,23 & 0,25 & 1,64 \\
\hline $\mathrm{CaO}$ & 4,60 & 3,59 & 4,21 & $<0,10$ & 3,70 & 3,58 & 1,27 & 1,11 & $<0,10$ & $<0,10$ & $<0,10$ & $<0,10$ \\
\hline $\mathrm{Na}_{2} \mathrm{O}$ & 3,73 & 3,59 & 3,43 & 0,12 & 2,76 & 2,78 & 3,09 & 3,62 & $<0,10$ & 2,57 & 4,04 & 0,65 \\
\hline $\mathbf{K}_{2} \mathbf{O}$ & 1,96 & 1,99 & 1,88 & 3,20 & 1,47 & 2,05 & 4,31 & 3,08 & 2,38 & 1,49 & 0,55 & 3,73 \\
\hline $\mathbf{P}_{2} \mathbf{O}_{5}$ & 0,16 & 0,16 & 0,08 & 0,10 & 0,30 & 0,19 & 0,07 & 0,08 & $<0,024$ & 0,05 & 0,03 & 0,08 \\
\hline LOI & 0,55 & 1,92 & 1,7 & 3,7 & 5,55 & 3,12 & 0,54 & 4,64 & 5,04 & 3,64 & 1 & 5,02 \\
\hline $\mathrm{FeO}$ & 2,86 & 2,14 & 2,54 & 4,15 & 1,47 & 1,12 & 1,36 & 0,95 & 0,34 & 1,08 & 0,62 & 3,95 \\
\hline \multicolumn{13}{|c|}{ Unidad Tad } \\
\hline Muestra & JR-266 & \multicolumn{2}{|c|}{ JR-271 } & JR-286 & JR-324 & JR-330 & JR-348 & JR-353 & JR-355 & IA-002 & JR-321 & GR-304 \\
\hline Longitud & $-75,1216$ & \multicolumn{2}{|c|}{$-75,0609$} & $-75,047$ & $-75,0964$ & $-75,139$ & $-75,1073$ & $-75,0467$ & $-75,0448$ & $-75,047$ & $-75,0967$ & $-75,126$ \\
\hline Latitud & 5,5695 & \multicolumn{2}{|c|}{5,6175} & 5,568 & 5,6004 & 5,5522 & 5,5727 & 5,4888 & 5,4892 & 5,4856 & 5,6085 & 5,5812 \\
\hline Elemento & $\% w t$ & \multicolumn{2}{|c|}{$\% w t$} & $\% w t$ & \%wt & $\% w t$ & \%wt & $\% w t$ & $\%$ wt & $\% w t$ & $\%$ wt & \%wt \\
\hline $\mathrm{SiO}_{2}$ & 69,51 & \multicolumn{2}{|c|}{61,71} & 58,60 & 72,21 & 69,25 & 75,53 & 65,78 & 66,12 & 61,68 & 68,55 & 67,78 \\
\hline $\mathrm{TiO}_{2}$ & 0,31 & \multicolumn{2}{|c|}{0,68} & 0,62 & 0,35 & 0,38 & 0,19 & 0,51 & 0,58 & 0,64 & 0,34 & 0,53 \\
\hline $\mathrm{Al}_{2} \mathrm{O}_{3}$ & 16,02 & \multicolumn{2}{|c|}{20,90} & 23,59 & 16,65 & 16,77 & 15,51 & 18,14 & 18,03 & 20,41 & 15,97 & 19,41 \\
\hline $\mathrm{Fe}_{2} \mathrm{O}_{3}$ & 1,15 & \multicolumn{2}{|c|}{5,09} & 5,08 & 2,19 & 1,23 & 0,60 & 3,68 & 3,71 & 4,03 & 1,47 & 3,06 \\
\hline MgO & 1,32 & \multicolumn{2}{|c|}{2,37} & 4,28 & 0,31 & 1,60 & 0,33 & 0,94 & 1,44 & 2,10 & 2,18 & 1,18 \\
\hline $\mathrm{CaO}$ & 3,87 & \multicolumn{2}{|c|}{3,27} & 3,44 & 0,92 & 2,56 & 0,01 & 3,19 & 2,78 & 3,67 & 3,24 & 1,06 \\
\hline
\end{tabular}


Continuación TABLA 2.

\begin{tabular}{|c|c|c|c|c|c|c|c|c|c|c|c|c|}
\hline \multicolumn{13}{|c|}{ Unidad Tad } \\
\hline Muestra & JR-266 & \multicolumn{2}{|c|}{ JR-271 } & JR-286 & JR-324 & JR-330 & JR-348 & JR-353 & JR-355 & IA-002 & JR-321 & GR-304 \\
\hline Longitud & $-75,1216$ & \multicolumn{2}{|c|}{$-75,0609$} & $-75,047$ & $-75,0964$ & $-75,139$ & $-75,1073$ & $-75,0467$ & $-75,0448$ & $-75,047$ & $-75,0967$ & $-75,126$ \\
\hline Latitud & 5,5695 & \multicolumn{2}{|c|}{5,6175} & 5,568 & 5,6004 & 5,5522 & 5,5727 & 5,4888 & 5,4892 & 5,4856 & 5,6085 & 5,5812 \\
\hline Elemento & $\% w t$ & \multicolumn{2}{|c|}{$\% w t$} & $\% w t$ & $\% w t$ & $\% w t$ & \%wt & $\% w t$ & $\% w t$ & $\% w t$ & $\% w t$ & \%wt \\
\hline $\mathrm{K}_{2} \mathrm{O}$ & 2,59 & \multicolumn{2}{|c|}{1,11} & 0,86 & 4,79 & 2,14 & 3,60 & 2,08 & 1,85 & 1,85 & 2,20 & 2,43 \\
\hline $\mathbf{P}_{2} \mathbf{O}_{5}$ & 0,13 & \multicolumn{2}{|c|}{0,08} & 0,03 & 0,13 & 0,16 & 0,04 & 0,24 & 0,21 & 0,17 & 0,12 & 0,12 \\
\hline LOI & 4,54 & \multicolumn{2}{|c|}{5,39} & 7,91 & 2,28 & 5,1 & 1,93 & 1,96 & 2,72 & 3,99 & 1,17 & 3,84 \\
\hline $\mathrm{FeO}$ & 1,4 & \multicolumn{2}{|c|}{1,42} & 1,3 & 0,13 & 1,7 & 0,44 & 0,51 & 1 & 1,39 & 1,29 & 0,64 \\
\hline \multicolumn{7}{|c|}{ Unidad Tadp } & \multicolumn{6}{|c|}{ Cuerpos dómicos } \\
\hline Muestra & GR-274 & JR-381 & JR-383 & JR-384-1 & JR-387-1 & JR-253-1 & JR-021-1 & IO-17-1 & JR-211-1 & JR-215-1 & IO-063-1 & ML-054 \\
\hline Longitud & $-75,1546$ & $-75,1488$ & $-75,149$ & $-75,1511$ & $-75,14$ & 5,65863 & $-74,9421$ & $-74,94$ & $-75,04709$ & $-75,04616$ & $-75,05265$ & $-75,0416$ \\
\hline Latitud & 5,6037 & 5,5977 & 5,5953 & 5,5896 & 5,5841 & $-74,945$ & 5,65912 & 5,65639 & 5,512 & 5,50991 & 5,51109 & 5,52189 \\
\hline Elemento & $\% w t$ & \%wt & $\% w t$ & $\% \mathrm{wt}$ & $\% w t$ & $\% w t$ & $\% w t$ & $\% w t$ & $\% w t$ & $\% w t$ & $\% w t$ & \%wt \\
\hline $\mathrm{SiO}_{2}$ & 68,50 & 66,67 & 59,07 & 62,28 & 65,93 & 69,58 & 70,38 & 54,30 & 62,23 & 61,69 & 61,32 & 64,86 \\
\hline $\mathrm{TiO}_{2}$ & 0,66 & 0,55 & 0,66 & 0,61 & 0,47 & 0,44 & 0,39 & 1,21 & 0,58 & 0,55 & 0,62 & 0,52 \\
\hline $\mathrm{Al}_{2} \mathrm{O}_{3}$ & 19,31 & 19,92 & 15,64 & 16,09 & 16,97 & 15,59 & 15,01 & 18,39 & 18,10 & 17,60 & 18,79 & 17,22 \\
\hline MgO & $<0,10$ & 2,11 & 6,31 & 3,94 & 2,19 & 1,69 & 1,58 & 5,66 & 2,61 & 3,41 & 3,18 & 2,13 \\
\hline $\mathrm{CaO}$ & 1,79 & 1,29 & 5,13 & 5,41 & 2,95 & 2,04 & 1,93 & 6,61 & 5,99 & 6,10 & 5,51 & 5,04 \\
\hline $\mathrm{Na}_{2} \mathrm{O}$ & 3,96 & 3,40 & 2,50 & 3,98 & 2,81 & 3,66 & 3,78 & 3,84 & 4,04 & 3,73 & 3,72 & 4,03 \\
\hline $\mathbf{K}_{2} \mathbf{O}$ & 2,33 & 2,14 & 3,00 & 2,11 & 2,94 & 2,71 & 2,71 & 1,23 & 1,29 & 1,45 & 1,23 & 1,65 \\
\hline $\mathbf{P}_{2} \mathrm{O}_{5}$ & 0,14 & 0,12 & 0,31 & 0,21 & 0,20 & 0,10 & 0,08 & 0,26 & 0,16 & 0,18 & 0,13 & 0,18 \\
\hline LOI & 3,39 & 4,68 & 6,51 & 5,98 & 4,37 & 0,75 & 0,44 & 2,37 & 0,71 & 1,54 & 2,8 & 1,05 \\
\hline $\mathrm{FeO}$ & 0,13 & 1,32 & 3,33 & 0,9 & 2,99 & 0,1 & 0,13 & 0,85 & 0,94 & 2,21 & 0,17 & 1,99 \\
\hline
\end{tabular}

En general todas las muestras, según el contenido de $\mathrm{K}_{2} \mathrm{O}$ vs $\mathrm{SiO}_{2}$ se ubican en el campo de la serie calcoalcalina (FIGURA 6C) en el diagrama de Peccerillo y Tylor (1976). La clasificación según Índice de Saturación de Alúmina (ASI) posiciona la mayoría de las muestras en el campo de rocas peraluminosas (FIGURA 6D) lo cual aportaría evidencia en principio de una fuente de fundido de un protolito de naturaleza pelítica o que el magma es muy diferenciado, pero como lo explica Miller (1985), el carácter peralumínico de este tipo de rocas podría estar ligado a fundido félsico metalumínico. Las muestras con un comportamiento fuertemente peraluminoso explicaría la concentración de alúmina presente en fases como moscovita, cordierita, granate, por otro lado, los comportamientos débilmente peralumínicos estarían relacionados a crecimiento de biotita alumínica. Lo anterior explicaría y reafirmaría el componente pelítico de la unidad Intrusivo Gnéisico (TRin) la cual muestra una mayor dispersión de rocas hacia el campo peraluminoso y cuya mineralogía está representada por moscovita, biotita, feldespato potásico, granate entre otros, y donde además, para el intrusivo gnéisico de Abejorral es reportada la paragénesis de cordierita + moscovita y para el de Rio Verde son reportados porfidoblástos de cordierita y feldespato potásico (Vinasco et al., 2006). Las demás unidades muestran un carácter metalumínico o ligeramente peralumínico. Los valores de ASI menores a 1 reflejarían un exceso de calcio ajustado en fases como anfíboles tipo hornblenda (Frost et al., 2001) vista en cierta abundancia en la mineralogía de la mayoría de las unidades. El diagrama de tipos de granitos de Chappell y White (1992) de la FIGURA $6 \mathrm{E}$ revela igualmente el posible carácter pelítico del fundido (granitoides tipo $\mathrm{S}$ ) de la unidad gnéisica (TRin) en relación con los demás cuerpos graníticos del área de estudio (Granitoides tipo I) y se confirma con la clasificación de tipo de protolito de Norman et al. (1992) para algunas de las muestras, mostrado en la FIGURA 6F. Según clasificación de Frost et al. (2001) los granitos de este trabajo se ubican en el campo de los tipos magnésicos y calco-alcalino y/o cálcicos (FIGURA 6G y 6H) característico de granitos cordilleranos o granitos de arco volcánico para Pearce et al. (1984). En la FIGURA 6G, se ubican en el área del promedio para rocas Mesozoicas graníticas tipo cordilleranas de América del Norte (Área morada). En esta misma figura son promediados leucogranitos peralumínicos o granitos tipo $\mathrm{S}$ producto de fundido metasedimentario. En este caso las muestras de la unidad gnéisica (símbolos verdes) tiene una mayor dispersión cayendo solo unas pocas en el promedio de rocas en Frost et al. (2001), aunque se presentan tanto como granitos magnésicos y férricos, mostrando como característica especial, el alto contenido de $\mathrm{SiO}_{2}$. Tanto la clasificación de Thiéblemont (1999) con elementos inmóviles como el Zr y Nb (FIGURA 6I) como la clasificación mediante $\mathrm{Y}, \mathrm{Nb}$ y $\mathrm{Rb}$ de Pearce et al. (1984) (FIGURA 6J y 6K) ubican las muestras en el campo rocas derivadas de magmatismo en zonas de subducción especialmente para las rocas más evolucionadas de carácter acido. 


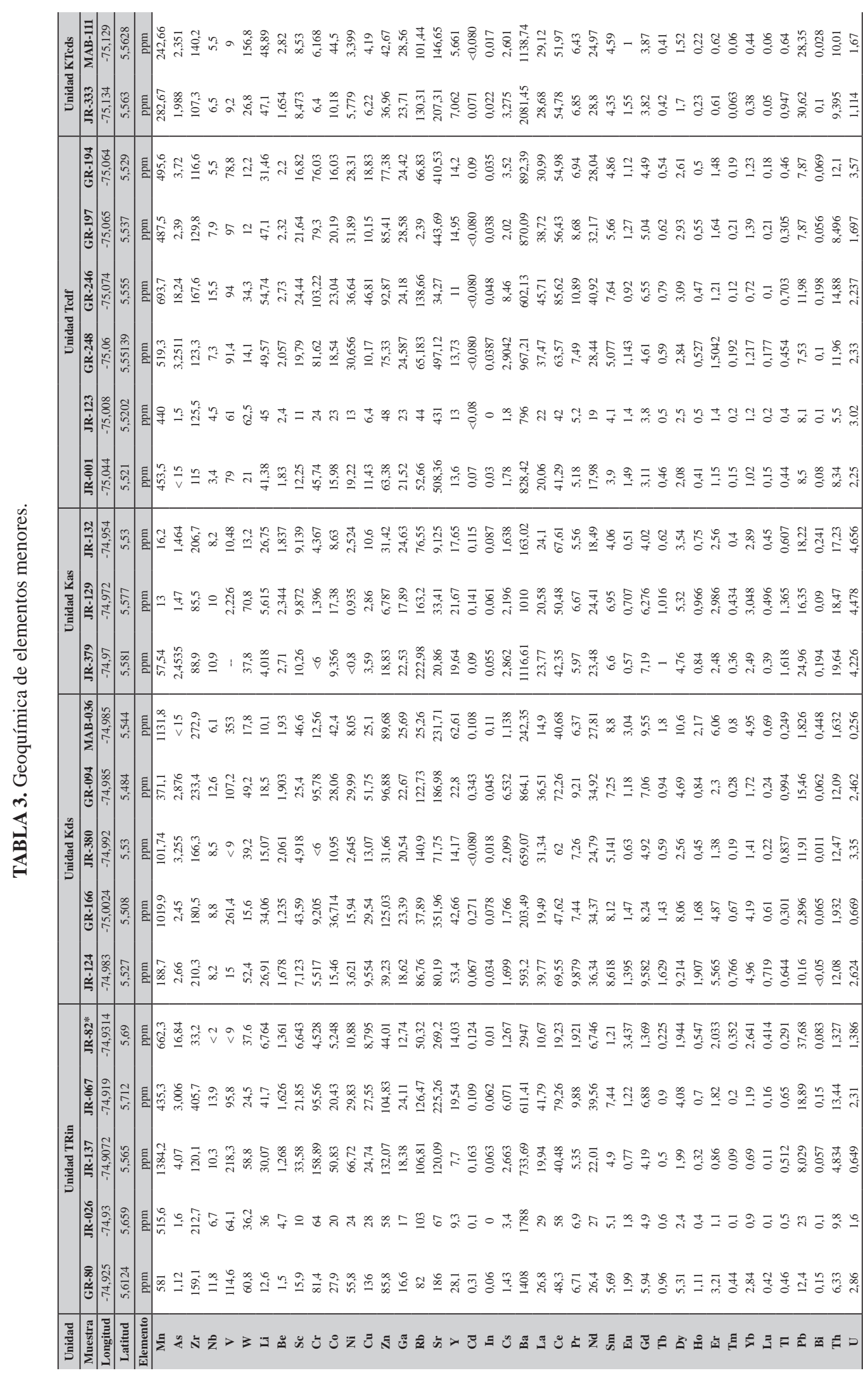




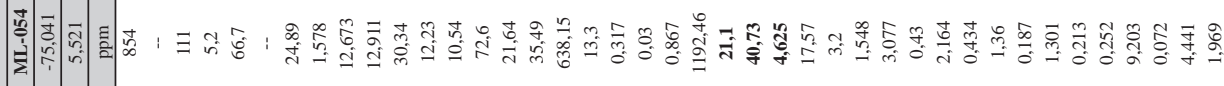

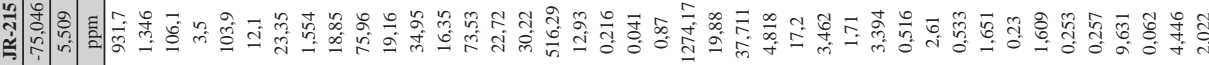

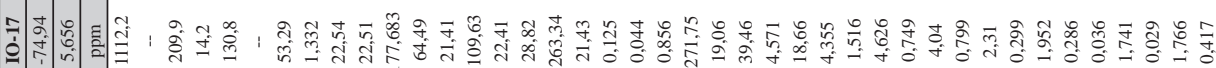

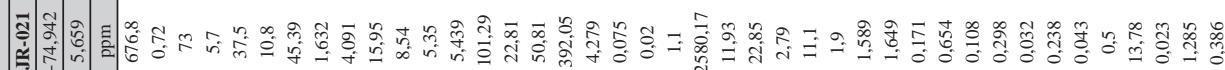

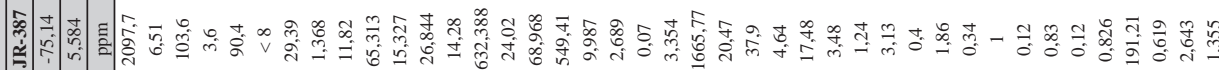

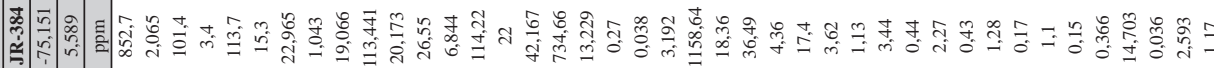

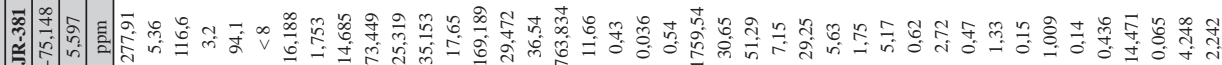

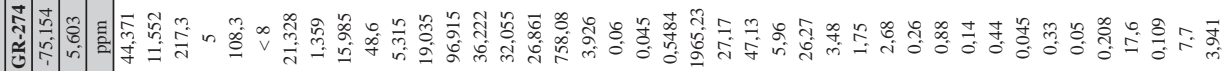

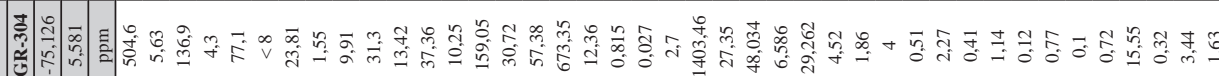

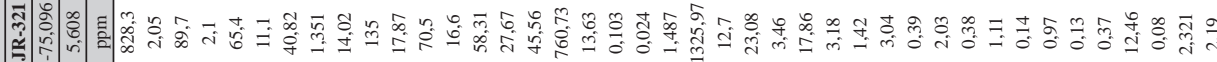

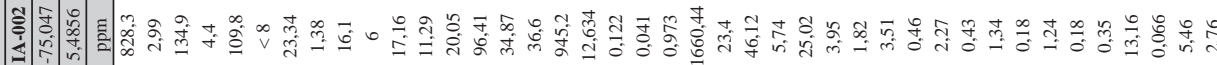

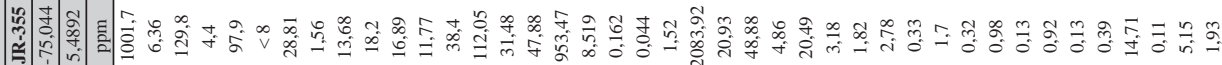

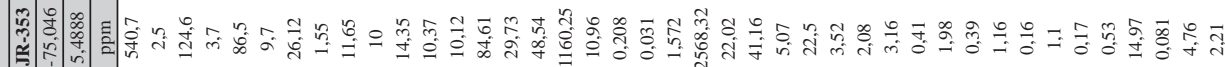

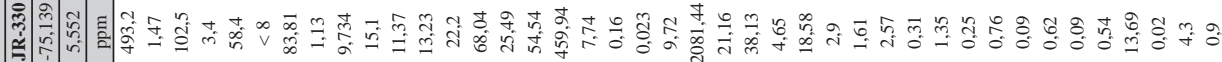

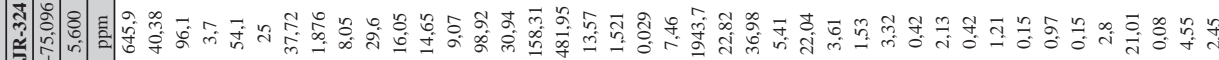

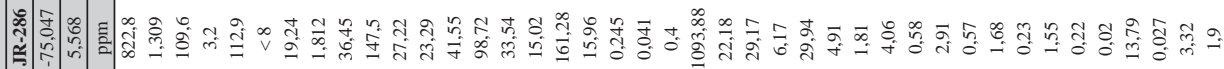

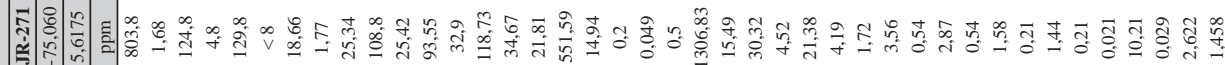

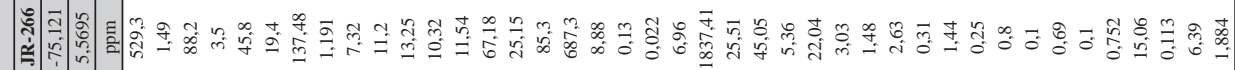

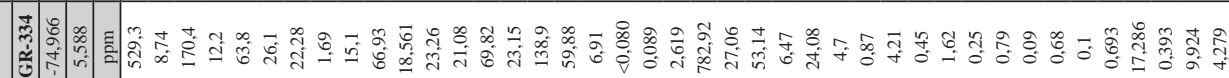

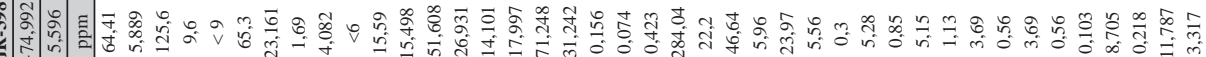

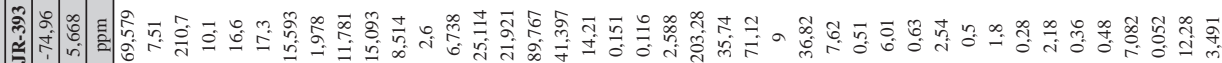

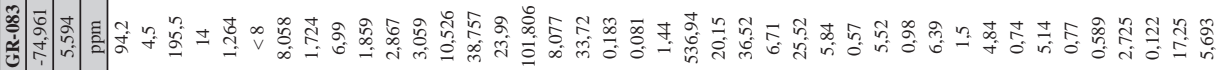



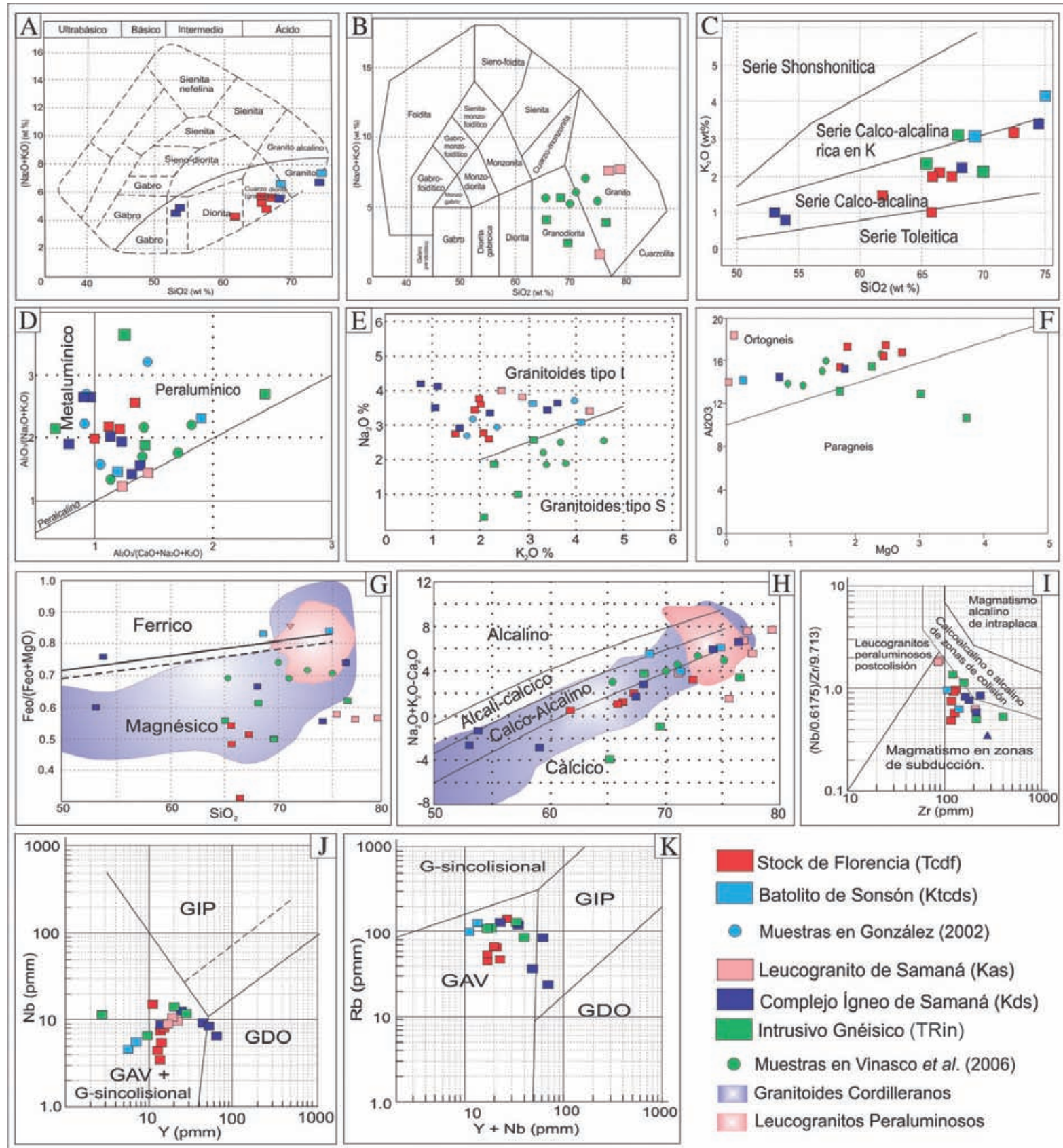

FIGURA 6. Clasificaciones químicas para los cuerpos plutónicos. A. Clasificación TAS para rocas plutónicas (Cox et al., 1979). B. Clasificación para rocas plutónicas saturadas en sílice (Middlemost, 1994). C. y D. Saturación de alúmina de Maniar y Piccoli (1989). E. Clasificación de tipo de granitos según valores $\mathrm{Na}_{2} \mathrm{O}$ y K $2 \mathrm{O}$ de granito (Chappell y White, 1992). F. Tipo de protolito de Norman et al. (1992). G. y H. Clasificaciones de Frost et al. (2001) teniendo presente cantidad de FeO-MgO y Na 2 , $\mathrm{K}_{2} \mathrm{O}$ y CaO respectivamente. I. Discriminación tectónica diagrama logarítmico de Thiéblemont (1999). J. y K. Discriminación tectónica (Pearce et al., 1984). GAV: Granitos de Arco Volcánico.

Respecto a los cuerpos porfiríticos, volcánicos y subvolcánicos, se colectaron 11 muestras de los pórfidos andesíticos (Tad), cuatro de los dacíticos (Td), seis del pórfido de Puente Linda (Tadp) y cuatro de los domos volcánicos (TABLAS 2 y 3). Se realizó el filtro de alteración de Wilt (1995) donde la mayoría de muestras caen en el campo de rocas frescas (FIGURA 7A y 7B), la excepción son las rocas dacíticas (Td) cuya mineralogía es claramente alterada, vista tanto en muestra de mano como bajo el microscopio. 
Los cuerpos andesíticos muestran valores de $\mathrm{SiO}_{2}$ entre 65,78 y $75,53 \%$ wt. $\mathrm{Al}_{2} \mathrm{O}_{3}$ entre 15,51 y 18,14 . $\mathrm{El} \mathrm{CaO}$ está entre 0,92 y $3,87, \mathrm{Na}_{2} \mathrm{O}$ entre 2,24 y 4,77 y $\mathrm{K}_{2} \mathrm{O}$ entre 4,79 y 1,85 . El contenido de $\mathrm{SiO}_{2}$ para las muestras JR-271-1 y JR-286-1 dan por debajo del promedio, con un rango de 61 a $58 \%$ wt respectivamente, igualmente los porcentajes de $\mathrm{Al}_{2} \mathrm{O}_{3}$ muestra valores elevados de 20,9 y 23,59 por encima de los otros cuerpos con excepción de la muestra IA-002-1 con 20,41 \%wt en $\mathrm{Al}_{2} \mathrm{O}_{3}$ y 61,68 en $\mathrm{SiO}_{2}$. Estas mismas muestras registras valores altos en $\mathrm{MgO}$ de 2,37 y 4,28 por encima del promedio de 1,28 para los demás cuerpos porfiríticos. La clasificación TAS posiciona estos cuerpos desde las andesitas hasta las dacítas y riolitas, aunque petrográficamente claramente caen en el campo de las andesitas con hornblenda, químicamente el contenido de $\mathrm{SiO}_{2}$ varia ampliamente seguramente por la variación de cuarzo modal, que en algunos casos, es más alto que los valores de plagioclasa (FIGURA 7C).

Para la unidad pórfido de Puente Linda los valores de $\mathrm{SiO}_{2}$ van de 59,07 a 68,50 \%wt. Los porcentajes de $\mathrm{Al}_{2} \mathrm{O}_{3}$ muestran valores de 15,64 a 19,92 \%wt aumentando a medida que aumenta la sílice, el $\mathrm{CaO}$ presenta variaciones importantes entre las muestras, por un lado hay valores mayores $5 \%$ wt y otro grupo que va de 1,29 a 2,95 \%wt. El $\mathrm{Na}_{2} \mathrm{O}$ y $\mathrm{K}_{2} \mathrm{O}$ muestran rangos de entre 2,50 a 3,98 y 2,14 a 3 \%wt respectivamente. Las muestras según clasificación TAS caen en el campo de las andesitas y dacitas (FIGURA 7C).

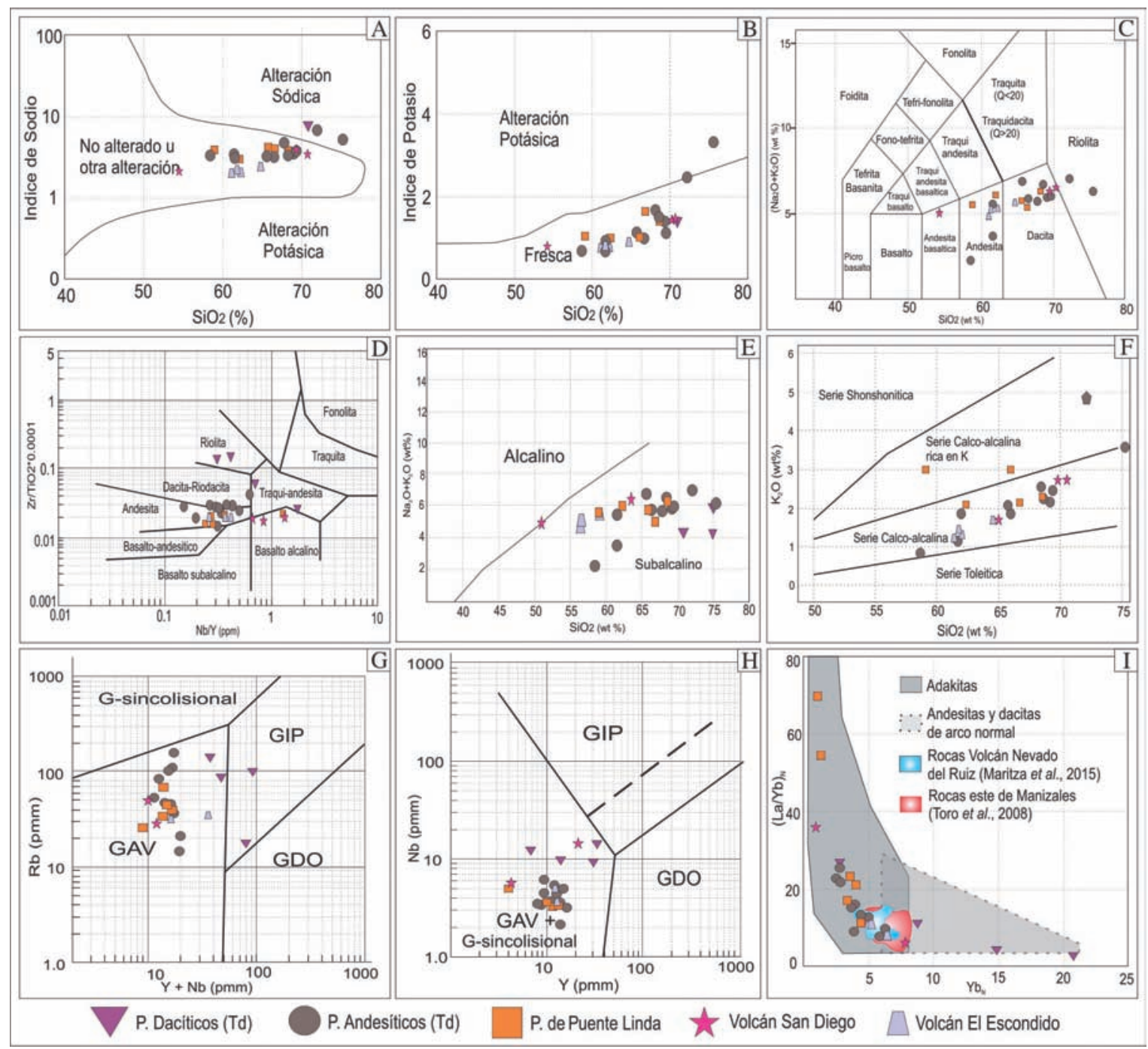

FIGURA 7. Clasificaciones químicas para los cuerpos porfiríticos. A. y B. Filtros de alteración (Wilt, 1995). C. Clasificación TAS. D. Clasificación de rocas porfiríticas (Winchester y Floyd, 1977). E. Clasificación de rocas subalcalinas (Peccerillo y Tylor, 1976). F. y G. Discriminación tectónica (Pearce et al., 1984). GAV: Granitos de Arco Volcánico. H. Clasificación de cuerpos porfiríticos en diagrama de Defant y Drummond (1990) para adakitas. I. Clasificación de cuerpos porfiríticos en diagrama de Martin (1999) para rocas adakiticas. En azul y rojo se muestran las rocas del Nevado de Ruiz y del este de Manizales. 
Los valores de la química de los cuerpos dacíticos (Td) como se esperaría para cuerpos tan ácidos, muestra concentraciones de $\mathrm{SiO}_{2}$ que sobrepasan el $75 \%$ wt para tres de las muestras $(79,82$ a 84,28 $\% w t)$ y solo una registra un valor menor de 71,32 \% wt. El contenido de $\mathrm{Al}_{2} \mathrm{O}_{3}$ está entre el 10 y $17 \%$ wt, para $\mathrm{Na}_{2} \mathrm{O}$ y el $\mathrm{K}_{2} \mathrm{O}$ los valores no son mayores al 4 y $3,7 \%$ wt respectivamente. $\mathrm{El} \mathrm{CaO}$ en todas las muestras da por debajo del límite de detección. Según clasificación TAS las muestras de los cuerpos porfiríticos dacíticos por su alto contenido de $\mathrm{SiO}_{2}$ se salen del área del diagrama.

Se utilizó el diagrama de Winchester y Floyd (1977), que permite hacer la clasificación con elementos inmóviles. La FIGURA 7D muestra que la mayoría de muestras grafican dentro del campo de las andesitas, para los cuerpos dacíticos se ve una dispersión entre riolitas y traqui-andesitas.

Las muestras del complejo de domos del volcán El Escondido caen en el campo de las andesitas, mientras que para el domo de San Diego se ubican en límites de las traqui-andesitas y basaltos alcalinos (FIGURA 7C).

Según el diagrama de Peccerillo y Tylor (1976) la mayoría de las muestras caen en el campo de rocas de serie subalcalina (FIGURA 7E), calcoalcalina con cuatro muestras en el campo de la serie calcoalcalina alta en potasio (FIGURA 7F). Por último, todas las muestras caen en el campo de los granitoides de arco volcánico según el comportamiento de $\mathrm{Rb}$ vs $\mathrm{Y}+\mathrm{Nb}$ y Nb vs Y (FIGURA 7G y 7H). Para las rocas porfiríticas volcánicas y subvolcánicas se graficó el diagrama de clasificación de rocas adakiticas (FIGURA 7I), donde se evidencia que todos los cuerpos dómicos (domos de los volcanes San Diego y El Escondido), los cuerpos denotados como porfiríticos andesíticos y el pórfido de Puente Linda se ubican en el campo de las adakitas.

El patrón de REE para los cuerpos volcánicos y subvolcánicos muestra lo siguiente. El patrón de REE en la unidad andesitas (Tad) (FIGURA 8A) de manera general presenta enriquecimiento de las LREE respecto a los las HREE, anomalía positiva en Eu con valores de $\mathrm{Eu}_{\mathrm{N}} / \sqrt{ }\left(\mathrm{Sm}_{\mathrm{N}} * \mathrm{Gd}_{\mathrm{N}}\right)$ desde 1,34 a 2,07. Para la unidad dacitica (Td) (FIGURA 8A) se nota un patrón con una mayor abundancia y dispersión de las HREE y con anomalía negativa en Eu con un valor de $\mathrm{Eu}_{\mathrm{N}} / \sqrt{ }\left(\mathrm{Sm}_{\mathrm{N}}{ }^{*} \mathrm{Gd}_{\mathrm{N}}\right)$ desde 0,18 a 0,64. Para la unidad pórfido de Puente Linda (FIGURA 8B) la dispersión de las concentraciones es menor que en los cuerpos anteriores mostrando homogeneidad en las LREE y dos patrones en la HREE. Una de estas rocas que muestra un patrón de HREE diferente, hace referencia a una roca colectada del contacto con esquistos verdes y cuya alteración era evidente.

Las cuatro muestras de los cuerpos volcánicos (FIGURA 8C) reflejan el mismo patrón de REE con ligeras variaciones en las cantidades muy seguramente debido al grado de diferenciación. Una de las muestras refleja un comportamiento anómalo especialmente en las HREE aunque muestra la misma tendencia. Todas muestran una anomalía ligeramente positiva de $\mathrm{Eu}_{\mathrm{N}} / \sqrt{ }\left(\mathrm{Sm}_{\mathrm{N}} * \mathrm{Gd}_{\mathrm{N}}\right)$ 1,45 a 4,76 para San Diego y de 1,65 a 1,11 para El Escondido.

La mayoría de los cuerpos plutónicos muestran anomalías negativas en Eu exceptuando algunas de la unidad TRin. Esta última unidad muestra variación en la HREE respecto a otras muestras de este cuerpo, pero en lugares diferentes, y aunque están mapeados como TRin, es claro que la mineralogía varía entre cuerpos; que este cambio sea de las HREE reflejaría variación en la presencia de granate en la fuente.

A diferencia de lo anterior, al menos dos muestras de la unidad Complejo de Samaná presentan un comportamiento casi planar y leve anomalía en Eu con valores de $\mathrm{Eu}_{\mathrm{N}} / \sqrt{ }\left(\mathrm{Sm}_{\mathrm{N}}{ }^{*} \mathrm{Gd}_{\mathrm{N}}\right)$ de 1,06 y ligeramente más enriquecidas en HREE, mientras que la misma unidad para las muestras graníticas registran valores de $\mathrm{Eu}_{\mathrm{N}} / \sqrt{ }\left(\mathrm{Sm}_{\mathrm{N}}{ }^{*} \mathrm{Gd}_{\mathrm{N}}\right)$ de 0,42 a 0,54 (FIGURA 8E).

Para el Stock de Florencia se observa un patrón de enriquecimiento de LREE respecto a las HREE es notoria una leve anomalía tanto positiva como negativa en Eu donde los valores de $\mathrm{Eu}_{\mathrm{N}} / \sqrt{ }\left(\mathrm{Sm}_{\mathrm{N}} * \mathrm{Gd}_{\mathrm{N}}\right)$ van de 0,43 a 0,8 para las anomalías negativas y de 1,19 y 1,42 para las positivas (FIGURA 8D). Los resultados del Batolito de Sonsón de las muestras analizadas aquí presentan un enriquecimiento de LREE respecto a las HREE con valores de $\mathrm{Eu}_{\mathrm{N}}$ ' $\left(\mathrm{Sm}_{\mathrm{N}}{ }^{*} \mathrm{Gd}_{\mathrm{N}}\right) 1 / 2$ de 1,26 y 0,78 mostrando una leve anomalía positiva y negativa. 


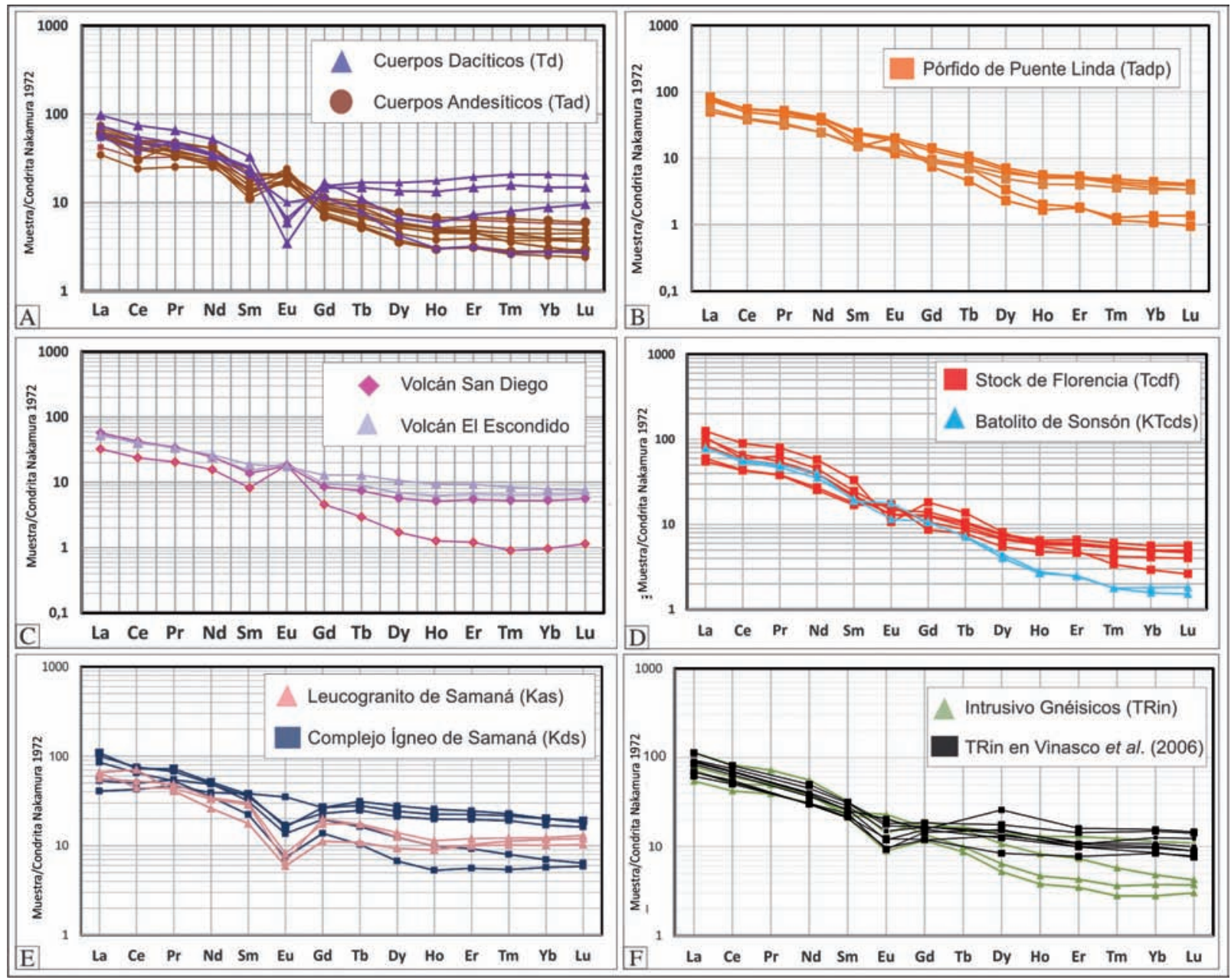

FIGURA 8. Abundancia de tierras raras (REE) vs Condrita de Nakamura (1974) para los cuerpos: A. y B. Subvolcánicos. C. Volcánicos. D. E. y F. Plutónicos.

\section{Geocronología}

A continuación se presentan los resultados de la geocronología mediante U-Pb por LA-ICP-MS en circones para cinco muestras y resultados Ar-Ar para dos muestras de los cuerpos dómicos, cuyos resultados se resumen en la TABLA 4 y FIGURAS 9 y 10.

TABLA 4. Resultados de edades U-Pb para cinco cuerpos plutónicos y Ar-Ar para tres volcánicos.

\begin{tabular}{|c|c|c|c|c|c|}
\hline \multirow{2}{*}{ Unidad } & \multicolumn{2}{|c|}{ Coordenada } & \multirow{2}{*}{ Tipo de roca } & \multirow{2}{*}{ Edad } & \multirow{2}{*}{ Método } \\
\hline & Latitud & Longitud & & & \\
\hline TRin & 5,6088 & $-74,9281$ & Monzogranito & $243 \pm 19$ & U-Pb (Circones) \\
\hline Kds & 5,5354 & $-74,9914$ & Diorita & $129,8 \pm 9,7$ & U-Pb (Circones) \\
\hline Kas & 5,5811 & $-74,9700$ & Granito & $132,8 \pm 2,6 \mathrm{Ma}$ & U-Pb (Circones) \\
\hline Tcdf & 5,5576 & $-75,0533$ & Granodiorita & $54,6 \pm 4,4 \mathrm{Ma}$ & U-Pb (Circones) \\
\hline KTcds & 5,5628 & $-75,1291$ & Granodiorita & $47 \pm 11 \mathrm{Ma}$ & U-Pb (Circones) \\
\hline Domo San Diego & 5,6586 & $-74,9452$ & Porfirítica dacítica & $89 \pm 4,4 \mathrm{Ka}$ & Ar-Ar en biotita \\
\hline Domo Florencia & 5,5099 & $-75,0461$ & Porfirítica andesítica & $153,7 \pm 38,5 \mathrm{Ka}$ & $\begin{array}{c}\text { Ar-Ar en } \\
\text { hornblenda }\end{array}$ \\
\hline $\begin{array}{l}\text { Cuerpo al W del D. } \\
\text { Florencia }\end{array}$ & 5,5095 & $-75,0532$ & Porfirítica andesítica & $55 \pm 23,6 \mathrm{Ka}$ & $\begin{array}{c}\text { Ar-Ar en } \\
\text { hornblenda }\end{array}$ \\
\hline
\end{tabular}


El evento más antiguo datado corresponde a la unidad Intrusivo Gnéisico a la cual se le hizo ablación a 63 puntos en un total de 46 cristales de los cuales 15 presentaba una zonación oscilatoria visible en las imágenes de catodoluminiscencia característica de circones ígneos. Al menos 21 ablaciones reportaron valores con porcentajes de discordias por encima del $100 \%$ con edades entre 200 mil y 2,5 Ma, las cuales fueron descartadas como la edad del evento. Dos edades recientes de $86,16 \pm 5,30$ y 78,43 $\pm 5,51 \mathrm{Ma}$, cuyas relaciones $\mathrm{Th} / \mathrm{U}$ presentan valores de 0,52 y 0,57, además su zonado concéntrico, sugerirían un origen ígneo. Los valores en los extremos de los cristales (último zonado o cierre del cristal) pueden ser interpretados como la fecha del evento metamórfico que afecto a este cuerpo, cuya edad dio $243 \pm 19$ Ma. En Barrero y Vesga (1976) reportan una edad de $207 \pm 7$ Ma para este mismo cuerpo muy cerca al punto de muestreo de este trabajo mientras que Vinasco et al. (2006) realizaron dataciones U-Pb y Ar-Ar para varios de los cuerpos denotados como granitos gnéisicos con edades de 230; 274 $\pm 9,6 ; 302 \pm 4 ; 290 \pm 10$ Ma. La variación de edades puede ser producto de la herencia de pulsos más recientes o la variación del metamorfismo en distintos lugares del mismo cuerpo.

El leucogranito o Alaskita de Samaná registra una edad de 132,8 $\pm 2,6$ Ma (FIGURA 9B) como resultado de 40 ablaciones en igual número de circones (FIGURA 9A) donde al menos cinco de estos cristales presentaban una zonación oscilatoria con relaciones Th/U de entre 0,5 y 0,9 (FIGURA 9C). Para el complejo de Samaná se realizaron 75 ablaciones en un total de 72 circones (FIGURA 9D) de los cuales a tres cristales se les realizó ablación en el núcleo y las zonaciones que mostraban con relaciones Th/U de entre 0,3 y 0,7 (FIGURA 9F). $\mathrm{Al}$ menos tres cristales registraron edades de mayores a 295 Ma consideradas como heredadas. Haciendo los recálculos la edad reportada es de 129,8 $\pm 9,7 \mathrm{Ma}$ (FIGURA 9E). Se tiene el reporte de edades menores p. ej. 119 \pm 10 en facie gabroica (Vesga y Barrero, 1978) mediante K-Ar (edad de enfriamiento), pero esta facie al menos en el área de norte de este trabajo se presenta como diques que cortan la facie tonalítica más general y cuya datación reporta la edad más alta.

Todas estas unidades cortan la secuencia metamórfica (complejo Cajamarca) cuya edad de metamorfismo sería anterior al Triásico (Vinasco et al., 2006), por lo que algunos de los circones heredados en las muestras datadas podrían provenir de dicha unidad y/o de núcleos más antiguos.
El Stock de Florencia se dató en circones con zonaciones sectorizadas y concéntricas y con relaciones Th/U típicas de circones de origen ígneo entre 0,3 y 0,8 (FIGURA 9I). Se reportó una edad de 54,6 $\pm 4,4$ Ma (FIGURA 9H), como resultado de la ablación de 64 puntos en igual número de cristales (FIGURA 9G), así como edades heredadas desde 150 hasta 500 Ma. Para el Batolito de Sonsón se realizaron 45 ablaciones en igual número de circones (FIGURA 9J), de ese total nueve mostraron edades de entre 115 y 290 Ma. La mayoría de los circones mostró una zonación sectorizada y unos pocos una zonación concéntrica o muy débilmente zonada con morfología de circones alargada y cuya relación de $\mathrm{Th} / \mathrm{U}$ fue bastante dispersa

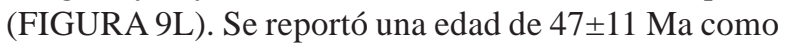
edad mínima de cristalización (FIGURA 9K).

Para el pórfido de Puente Linda se realizó ablación a un total de 88 puntos (FIGURA 9M) para el mismo número de circones con zonaciones poco evidentes, al menos 6 de estos circones mostraban un núcleo aparente donde se procedió a hacer la ablación. Cuatro edades registradas sobrepasan los $40 \mathrm{Ma}$, por lo que son consideradas como heredadas. Los valores de la relación Th/U se enmarcan entre 0,1 y 0,5 (FIGURA 9O) con edades entre 1,7 y 2,3 Ma, y se consideran evidencia de datos que reflejan el evento ígneo. La edad reportada es de 2,1 $\pm 1,9$ Ma (FIGURA 9N).

El domo de San Diego, uno de los domos de Florencia y un cuerpo porfirítico en el mismo sector de Florencia pero al oeste del complejo de domos del volcán El Escondido se dataron mediante Ar-Ar (FIGURA 10).

Para el domo de San Diego se registró una edad de $89 \pm 4,4 \mathrm{Ka}$ (FIGURA 10A). Teniendo presente lo propuesto en Monsalve (2015) y Monsalve et al. (2014), los depósitos piroclásticos de este volcán estarían asociados a una actividad posterior a la intrusión del cuerpo dómico y por lo cual deberían presentar edades mucho más jóvenes que esta estructura. Por otro lado, es posible pensar en que el domo tuviera su formación antes de la actividad freática del maar y que los depósitos que mantelan desde la superficie al domo, no provengan de este, sino más bien fueron dirigidos desde el cráter hacia el NE, mantelando así la estructura dómica. Trabajos como el de WoodwarClyde Consultants (1980) registran este domo con una edad menos a 50.000 años y Toro (1991) reporta una edad de 18.700 años con un error considerable de \pm 10.000 . 

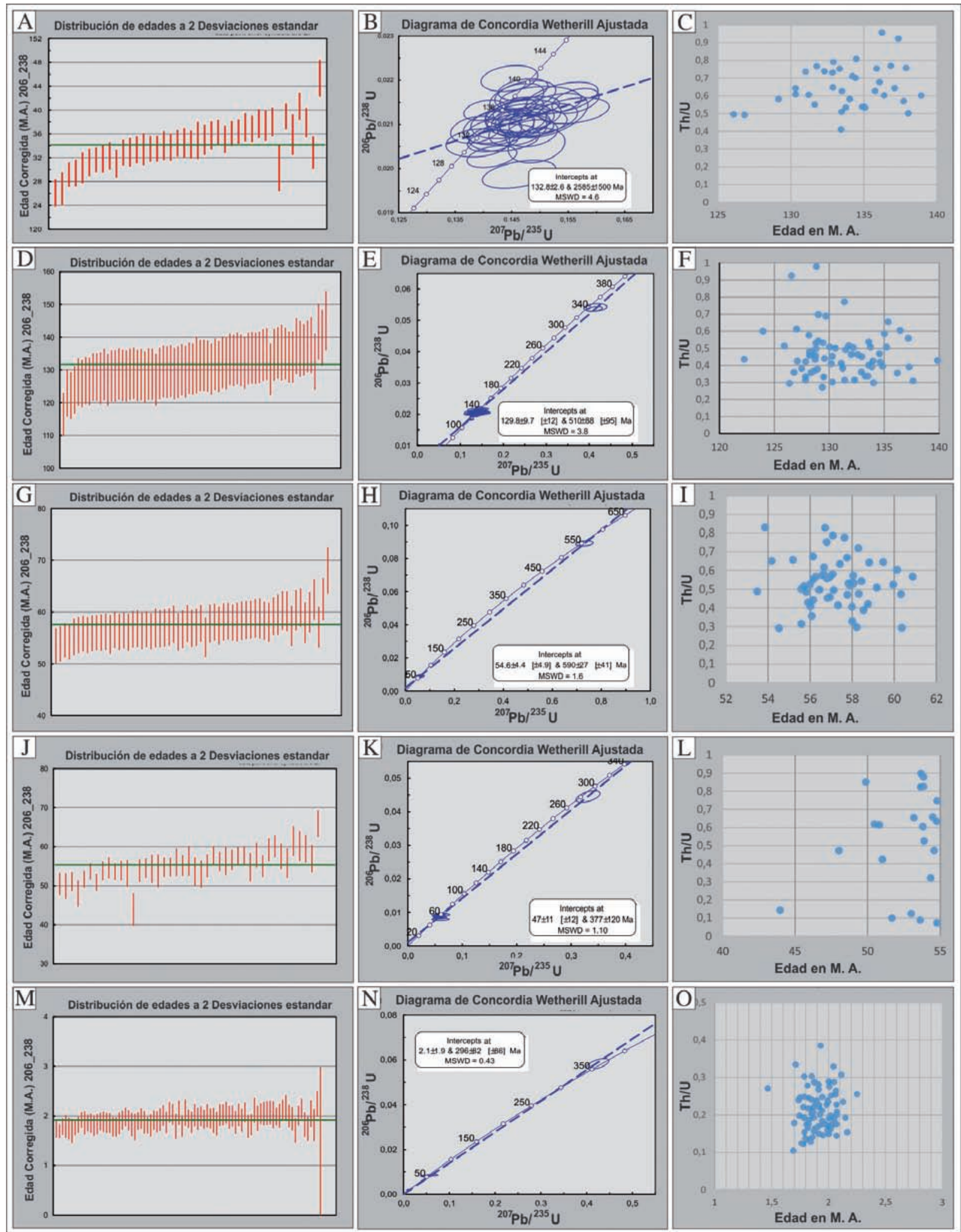

FIGURA 9. Histograma de edades, diagrama de concordia y relación $\mathrm{Th} / \mathrm{U}$ (sin edades heredadas) respectivamente de izquierda a derecha. A, B y C. Unidad Alaskita de Samaná. D, E y F. Unidad Complejo Ígneo de Samaná. G, H y I. Unidad Stock de Florencia. J, K y L. Unidad Batolito de Sonsón. M, N y O. Unidad Pórfido de Puente Linda. 

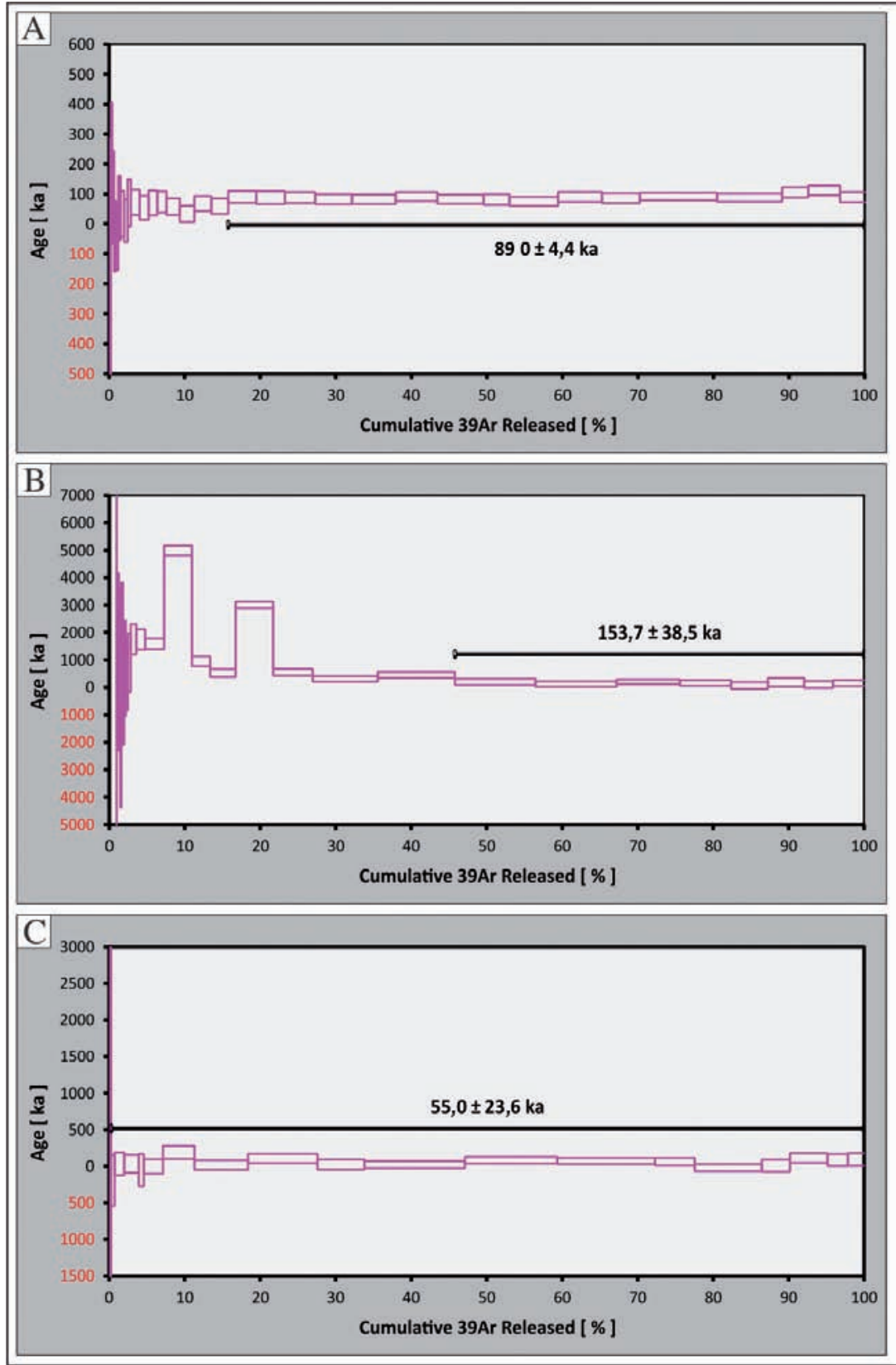

FIGURA 10. Diagrama de edad Plateau para los cuerpos dómicos. A. Domo San Diego. B. Domo del Florencia (Volcán El Escondido). C. Estructura al oeste del Domo de Florencia.

La datación de uno de los domos de Florencia (Volcán El Escondido) con una edad de $153,7 \pm 38,5 \mathrm{Ka}$ (FIGURA 10B) representa un problema puesto que dicho complejo está asociado a la última actividad intracaldérica del volcán El Escondido cuyos depósitos volcánicos están datados en alrededor de los $33 \mathrm{Ka}$ (Monsalve et al., 2014; Monsalve 2015). La datación del domo supone que la actividad efusiva fue mucho antes que la actividad que dio lugar a los depósitos de los alrededores del volcán. Por otro lado, la estructura al $\mathrm{W}$ del domo refleja una edad de $55 \pm 23,6 \mathrm{Ka}$ (FIGURA 10C), cuyo error daría un margen a favor para correlacionar dicha estructura, con la actividad explosiva del volcán.

\section{DISCUSIÓN}

Las intrusiones plutónicas, sobvolcánicas y volcánicas de firma calcoalcalina y afinidad adakitica para los cuerpos recientes (unidades porfiríticas menores a $2 \mathrm{Ma}$ ) 
registran una intensa evolución magmática cuyos pulsos se emplazaron en varios niveles de la corteza. La unidad Intrusivo Gnéisico refleja un evento sobreimpuesto de deformación (sintectónica), planteando la discusión de la forma como se le debe llamar a este cuerpo. Las intrusiones cretácicas (complejo de Samaná y leucogranito o Alaskita de Samaná) muestran edades muy similares y se pueden interpretar como una evolución de un mismo pulso dando origen a la variedad de litologías dentro del complejo, como a la fase más evolucionada representada por granitos leucocraticos. Los cuerpos paleógenos (Batolito de Sonsón y Stock de Florencia) muestran similitudes en petrografía (relación porcentual de cuarzo, plagioclasa y feldespatos, microclina y albita para el Stock y para el Batolito de Sonsón ortoclasa, albita, labradorita) y geoquímica (REE y elementos traza, con anomalías negativas en $\mathrm{Nb}$ y $\mathrm{Ti}$ ) sugiriendo un mismo pulso con diferencias geocronológicas muy mínimas en su cristalización.

De gran interés resulta la edad registrada para el Batolito de Sonsón, pues los antecedentes reportan dos edades tanto Paleógenos como Triásicas. Esta edad abre la discusión respecto a las otras dataciones registradas en otras partes del Batolito y por diferentes autores. Por un lado González (1980, 2002) mediante $\mathrm{K}-\mathrm{Ar}$ en roca total registró valores de $170 \pm 10 \mathrm{Ma}$ y $160 \pm 4$ Ma. Pérez (1967) mediante K/Ar reporta una edad de 69,3 \pm 3 Ma, Ordoñez et al. (2001) reporta edad de cristalización de 60,7 $\pm 1,4$ Ma mediante SHRIMP $\mathrm{U}-\mathrm{Pb}$ en zircones y Leal-Mejía (2011) mediante el método U-Pb en circones con LA-MC-ICP-MS reporta una edad de 58,6 60,9 Ma para una granodiorita, facie principal del Batolito y 55,8 $\pm 0,9$ Ma y 60,0 $\pm 0,09$ Ma para dos leucogranitos, todas estas dataciones realizadas al norte del Batolito. Tanto Ordoñez et al. (2001) como Leal-Mejía (2011), soportan la idea de una edad Paleógena para la parte norte del batolito que difiere química e isotópicamente de la parte sur de esta misma intrusión (línea amarilla y morada en FIGURA 1). Esta nueva fecha pondría al Batolito de Sonsón al menos es su parte central y más oriental en el Paleoceno y no en el Jurásico, lo que reflejaría claramente que se trata de un cuerpo diferente al denotado como Batolito de Sonsón.

Las edades de los cuerpos dómicos relacionados a la actividad reciente se relacionan con dataciones de algunos cuerpos porfiríticos de la zona con edades entre 400.000 años y poco más de 1 Ma (Leal-Mejía, 2011) lo que demuestra la continua actividad del arco magmático de la cordillera central y por lo tanto el continuo aporte de calor a la zona de estudio.
Aunque las fuentes termales se relacionan, por ubicación geográfica y química, con la actividad volcánica del maar de San Diego y El Escondido, en el sector de Puente Linda, donde también hay manantiales termales y, teniendo en cuenta las características de los cuerpos subvolcánicos, no se descarta la presencia de una anomalía térmica (intrusión) sin una expresión superficial.

\section{CONCLUSIONES}

La actividad ígnea del costado oriental de la Cordillera Central refleja intrusiones de batolitos y stocks graníticos y granodioríticos relacionados a diferentes arcos magmáticos y series calcoalcalina formando magmas tipo I e Intrusivo Gnéisico Triásico tipo S. En general la química de las REE para los cuerpos graníticos muestra enriquecimiento en LREE y empobrecimiento en HREE, se diferencia para rocas gabróicas-dioríticas de la unida Kds un comportamiento más planar (menos diferenciado) en las REE. Anomalías negativas o ligeramente positivas en $\mathrm{Eu}$ en la mayoría de muestras son visibles. Estos pulsos registran edades de cristalización desde el Cretáceo inferior para las unidades Kds y Kas con $129,8 \pm 9,7$ Ma y $132,8 \pm 2,6$ Ma respectivamente, hasta el Paleógeno con la unidad Tcdf que reporta 54,6 $\pm 4,4$ Ma y el Batolito de Sonsón con 47£11 Ma.

Actividad más reciente representada por los cuerpos porfiríticos de carácter subvolcánico y dómico (volcánicos), de composición andesítica con hornblenda, dacíticos con hornblenda y biotita y el carácter vítreo de algunas muestras, son clara muestra de la continuidad de la actividad magmática cerca de la superficie. Químicamente estas rocas se dan en el campo de las andesitas hasta el límite dacíticoriolítico. La geoquímica posiciona estos cuerpos como vulcanismo de subducción de serie calcoalcalina de carácter adakítico. El comportamiento de las REE es similar en la mayoría con una diferencia notable en la anomalía negativa de Eu para los cuerpos dacíticos y positiva para los demás cuerpos andesíticos (Tad) incluyendo los domos volcánicos, reflejando esto la ausencia de plagioclasa para los primeros y presencia para los segundos, siendo este un mineral que acomoda más Eu en su estructura, y aclarando que la composición química reportada aquí es de roca total que incluye la matriz y los fenocristales. Las dataciones Ar-Ar posicionan los cuerpos dómicos en los $89 \pm 4,4$

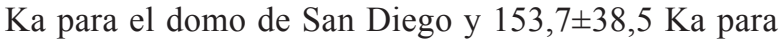
uno de los domos del volcán El Escondido, lo que evidencia la continua actividad efusiva en la zona y 
cuyos resultados preliminarmente suponen que dicha actividad podría ser anterior a los eventos explosivos que produjeron la pila de depósitos volcánicos de la zona.

Los cuerpos de carácter subvolcánico de composiciones acidas e intermedias con intensa alteración, dan evidencian de interacción fluido-roca que reafirman la debilidad estructural y apertura de la roca que proporcionan el paso de fluidos calientes (Falla Rio Dulce) para el sector occidental. De igual manera estructuras como el volcán San Diego podrían ser el resultado de desarrollo de fallas (Palestina, San Diego y Patio Bonito) y la debilidad en los límites entre los cuerpos intrusivos y un basamento pelítico fuertemente foliado. Por otro lado, la presencia de termales en límites de los cuerpos intrusivos o cercanos a ellos, reflejan anomalías térmicas cuyas fuentes podrían ser relacionadas a la evidente actividad volcánica de la zona o a pulsos magmáticos sin expresión superficial.

\section{AGRADECIMIENTOS}

Se agradece al Servicio Geológico Colombiano el cual cumpliendo con los objetivos misionales, permitió la realización de este trabajo dentro del marco de los estudios realizados por el Grupo de Investigación y Exploración de Recursos Geotérmicos; se agradece a la geóloga Gina Z. Rodríguez quien hizo parte de las labores de campo del área geotérmica de San Diego cuyos resultados se plasman en el documento de Rueda y Rodríguez (2016); al geólogo Gabriel Rodríguez del SGC sede Medellín por la asesoría suministrada. A todos los profesionales y técnicos del laboratorio químico del SGC así como a los miembros del grupo de Geotermia que hicieron parte de una u otra forma de este trabajo (Miguel Beltrán, Claudia Alfaro, Iván Ortiz, Maria L. Monsalve, Iván Adarme entre muchos más).

\section{REFERENCIAS}

Barrero, D., y Vesga, C. (1976). Geología de la Plancha 188, La Dorada. Mapa Geológico. INGEOMINAS.

Caceres, A. (2012). Genesis of the sediment-hosted uraniferous phosphate deposit in the Berlin Project, Central Cordillera, Colombia and its implications for exploration. M.Sc. Thesis, Queen’s University, Ontario, Canada.
Chappell, B.W., and White, A.J.R. (1992). I- and S-type granites in the Lachlan Fold Belt. Earth and Environmental Science Transactions of the Royal Society of Edinburgh, 83(1-2), 1-26.

CHEC. (1968). Proyecto de investigación geotérmica en la Región del Macizo Volcánico del Ruiz. Central Hidroeléctrica de Caldas S.A., Manizales, Colombia.

CHEC. (1981). Investigación geotérmica en la Región del Macizo Volcánico del Ruiz (Colombia). Central Hidroeléctrica de Caldas S.A. Fase I. Informe Final.

Cox, K.G., Bell J.D., and Pankhurst, R.J. (1979). The interpretation of igneous rock. London: Allen and Unwin.

Barrero, D. y Vesga J. (1976). Compiladores Geología de la Plancha 188, La Dorada. Mapa Geológico. INGEOMINAS.

Defant, M.J. and Drummond, M.S. (1990). Derivation of some modern arc magmas by melting of young subducted lithosphere. Nature, 347, 662-665. doi: 10.1038/347662a0.

Feininger, T. (1970). The Palestina fault, Colombia. Geological Society of America Bulletin, 81, 12011216.

Feininger, T., Barrero, D., y Castro, N. (1972). Geología de parte de los departamentos de Antioquia y Caldas (Subzona II-B). Boletín Geológico, 20(2), $1-173$.

Feininger, T., Barrero, D., Castro, N., Ramírez, O., Lozano, H., y Vesga, J. (1970). Geología de la Plancha 168, Argelia. Mapa Geológico. INGEOMINAS.

Florez, M.T. (1987). Litoestratigrafía para Las Tefras de la Unión y San Diego. I Seminario "Gerardo Botero Arango", UNAL - INGEOMINAS, Medellín, Colombia.

Frost, R.B., Barnes, C.G., Collins, W.J., Arculus, R.J., Ellis, D.J., and Frost, C.D. (2001). A geochemical classification for granitic rocks. Journal of Petrology, 42(11), 2033-2048. doi: 10.1093/ petrology/42.11.2033. 
Gómez, J., Montes, N.E., Alcárcel, F.F., y Ceballos, J.A. (2015a). Catálogo de dataciones radiométricas de Colombia en ArcGIS y Google Earth. En: J. Gómez, M.F. Almanza. (eds). Compilando la geología de Colombia: Una visión 2015 (pp. 63-419). Servicio Geológico Colombiano, Publicaciones Geológicas Especiales 33. Bogotá, Colombia.

Gómez, J., Montes, N.E., Nivia, Á., y Diederix, H. Compiladores. (2015b). Mapa Geológico de Colombia 2015. Escala 1:1.000.000. Servicio Geológico Colombiano, Bogotá, Colombia.

González, H. (1980). Geología de las planchas 167, Sonsón y 187, Salamina, del mapa geológico de Colombia (Antiguo Cuadrángulo J-8). Boletín Geológico, 23(1), 1-174.

González, H. (1990). Mapa geológico del departamento de Caldas. Escala 1:250.000. Memoria explicativa. INGEOMINAS.

González, H. (2002). Catálogo de unidades litoestratigráficas de Colombia. Batolito de Sonsón (Jts). Instituto de Investigación e Información Geocientífica, Minero-Ambiental y Nuclear.

González, H., Agudelo, S., y Calle, Z. (1980a). Geología de la Plancha 187, Salamina. Mapa Geológico. INGEOMINAS.

González, H., Agudelo, S., y Calle, Z. (1980b). Geología de la Plancha 167, Sonsón. Mapa Geológico. INGEOMINAS.

IGAC. (1961). Carta general del departamento de Caldas. Planchas 188IA, 188IB, 188IC, 188ID, escala 1:25.000. Instituto Geográfico Agustín Codazzi, Bogotá.

IGAC. (1979). Carta general del departamento de Antioquia. Planchas. 168IIIB, escala 1:25.000. Instituto Geográfico Agustín Codazzi, Bogotá.

Leal-Mejía, H. (2011). Phanerozoic gold metallogeny in the Colombia Andes: A tectono-magmatic approach. Tesis Doctoral, Universitat de Barcelona, España.

Loaiza, D.G. (2012). Caracterización geológica y geoquímica con fines de exploración, análisis petrográfico y metalográfico e identificación de zonas anómalas de mineralizaciones polimetálicas de plomo, zinc, cobre ( $\mathrm{Pb}, \mathrm{Zn}, \mathrm{Cu})$ y metales preciosos: oro, plata (Au-Ag) en el pórfido dacítico (Adakitico) "El Morro" y el "Complejo Ígneo de Samaná” (Granodiorita, Alaskita, Agmatitas) al NE del Municipio de Samaná, Departamento de Caldas. Tesis, Universidad de Caldas, Manizales, Colombia.

López, J., Cuéllar, MA., Aguirre, R., Valencia, M., y Sánchez, A. (2007). Evidencias petrográficas y de campo de una intrusión sintectónica en la Cordillera Central de Colombia: El Caso de la Milonita Granítica del Guacaica. IX Congreso Colombiano de Geología, Bucaramanga, Colombia.

Maniar, P.D., and Piccoli, P.M. (1989). Tectonic discrimination of granitoids. Geological Society of America Bulletin, 101(5), 635-643. doi: 10.1130/0016-7606(1989)101<0635:TDOG >2.3. $\mathrm{CO} ; 2$.

Maritza, L., Valencia, J., Ceballos, J., Narváez, L., Pulgarín, B., Correa, A., Murcia, H., Zuluaga, I., Rueda, J., y Pardo, N. (2015). Geología y estratigráfica del Complejo Volcánico Nevado del Ruiz. Informe Técnico. Servicio Geológico Colombiano.

Martin, H. (1999). The adakitic magmas: modern analogues of Archean granitoids. Lithos, 46(3), 411-429. doi: 10.1016/S0024-4937(98)00076-0.

Middlemost, E.A.K. (1994). Naming materials in the magma/igneous rock system. Earth-Science Reviews, 37(3-4), 215-224. doi: 10.1016/00128252(94)90029-9.

Miller, C.F. (1985). Are strongly peraluminous magmas derived from pelitic sedimentary sources?. Journal of Geology, 93(6), 673-689.

Monsalve, M.L. (2015). Vulcanismo del área geotérmica de San Diego. Informe de Avance. Servicio Geológico Colombiano.

Monsalve, M.L., y Ortíz, I. (2013). Reconocimiento vulcanológico área geotérmica de San Diego. Servicio Geológico Colombiano.

Monsalve, M.L., Ortiz, I., and Norini, G. (2014). Deposits associated to San Diego Maar 
(Colombia). IAVCEI-5th International Maar Conference. Querétaro.

Monsalve, M.L., Ortiz, I., and Norini, G. (2017). El Escondido, a newly identified silicic Quaternary volcano in the NE region of the northern volcanic segment (Central Cordillera of Colombia). Journal of Volcanology and Geothermal Research. doi: 10.1016/j.jvolgeores.2017.12.010.

Nakamura, N. (1974). Determination of REE, Ba, Mg, $\mathrm{Na}$, and $\mathrm{K}$ in carbonaceos and ordinary chondrites. Geochemical et Cosmochimical Acta, 38(5), 757775. doi: 10.1016/0016-7037(74)90149-5.

Norman, M., Leeman, W., and Mertzman, S.A. (1992). Granites and rhyolites from the northwestern USA: temporal variation in magmatic processes and relations to tectonic setting. Earth and Environmental Science Transactions of the Royal Society of Edinburgh, 83(1-2), 71-81. doi: 10.1017/S0263593300007768.

Ordoñez, O. (2001). Caracterização isotópica Rb-Sr e Sm-Nd dos principais eventos magmáticos nos Andes Colombianos. Ph.D. thesis, Universidade de Brasilia, Brasilia, Brasil.

Page, W.D. (1986). Seismic Geology and Seismicity of Northwestern Colombia. Compilación ISA. Medellín.

Pearce, J.A., Harris, B.W., and Tindle, A.G. (1984). Trace elements discrimination diagrams for the tectonic interpretation of granitic rocks. Journal of Petrology, 25(4), 956-983. doi: 10.1093/ petrology/25.4.956.

Peccerillo, A., and Taylor, S.R. (1976). Geochemistry of Eocene calc-alkaline volcanic rocks from the Kastamonu area, Northern Turkey. Contributions to Mineralogy and Petrology, 58(1), 63-81. doi: 10.1007/BF00384745.

Peña-Ureña, M.L., Muñoz-Rocha, J.A., y Urueña, C.L. (2018). Laboratorio de geocronología en el Servicio Geológico Colombiano: Avances sobre datación U-Pb en circones mediante la técnica LA-ICP-MS. Boletín Geológico, 44, 39-56.

Pérez, G. (1967). Determinación de la edad absoluta de algunas rocas de Antioquia por métodos radioactivos. Dyna, 84, 27-31.
Pimiento, R. (2011). Mineralogía y petrografía de la mineralización de uranio en fosforitas del cretácico inferior, sinclinal de Berlín, Cordillera Central, (departamento de Caldas, Colombia). Tesis, Universidad Industrial de Santander, Bucaramanga, Colombia.

Rueda, J.B. y Rodríguez, G.Z. (2016). Geología del área geotérmica de San Diego. Servicio Geológico Colombiano. Informe Técnico, Bogotá.

Ríos-Guerrero, L.J. (2012). Estratigrafía y ambiente de depósito del Sinclinal de Berlín, Municipio de Caldas (Colombia). Tesis de Grado, Universidad Industrial de Santander, Bucaramanga, Colombia.

SGC. (2013). Inventario Nacional de Manantiales. Servicio Geológico Colombiano. Consultado el 14 de diciembre de 2017. http://hidrotermales. sgc.gov.co/.

Thiéblemont, D. (1999). Discrimination entre magmatismes calco-alcalins mantellique et crustal, l'exemple des Andes. Comptes Rendus de l'Academie des Sciences- Series IIA - Earth and Planetary Science, 329(4), 243-250. doi: 10.1016/ S1251-8050(99)80242-0.

Toro, G. (1989). Caracterización del volcanismo de San Diego y estudios de los depósitos de San Diego (Caldas) y Nariño (Antioquia), Colombia. VI Congreso Colombiano de Geología. Bucaramanga, Colombia.

Toro, G. (1991). Geología de la zona del volcán de San Diego, departamento de Caldas Colombia. I Simposio Magmatismo Andino. Manizales, Colombia.

Vesga, C.J., y Barrero, D. (1978). Edades K/Ar en rocas ígneas y metamórficas de la Cordillera Central de Colombia y su implicación geológica. II Congreso Colombiano de Geología, Bogotá, Colombia.

Vinasco, C.J., Cordani, U.G., González, H., Weber, M., and Pelaez, C. (2006). Geochronological, isotopic, and geochemical data from PermoTriassic granitic gneisses and granitoids of the Colombian Central Andes. Journal of South American Earth Sciences, 21(4), 355-371. doi: 10.1016/j.jsames.2006.07.007. 
Wilt, J.C. (1995). Correspondence of alkalinity and ferric/ferrous ratios of igneous rocks associated with various types of porphyry copper deposits. In: F.W. Pierce, J.G. Bolm (eds.). Porphyry copper deposits of the American Cordillera (pp. 180-200). Arizona Geological Society Digest 20.

Winchester, J.A., and Floyd, P.A. (1977). Geochemical discrimination of different magma series and their differentiation products using immobile elements. Chemical Geology, 20, 325-343. doi: 10.1016/0009-2541(77)90057-2.
Woodward-Clyde Consultants. (1980). Prelyminary Seismic Hazard Study San Carlos Proyect Colombia. Report to Interconexion Electrica S.A. and Integral. LTDA. Medellín, Colombia. Stage A, phase I.

\begin{tabular}{c}
\hline \hline Jesús Bernardo Rueda-Gutiérrez \\
ORCID: 0000-0002-5575-4702 \\
\hline \hline
\end{tabular}

Trabajo recibido: mayo 16 de 2018

Trabajo aceptado: abril 30 de 2019 